\begin{abstract}
UNIVERSIDADE DE BRASÍLIA
FACULDADE DE EDUCAÇÃO FÍSICA

PROGRAMA DE PÓS-GRADUAÇÃO STRICTO-SENSU EM EDUCAÇÃO FÍSICA
\end{abstract}

EFEITOS DE EXERCÍCIOS PROPRIOCEPTIVOS NO EQUILÍBRIO POSTURAL E NA ATIVIDADE ELETROMIOGRÁFICA DE EXTENSORES DO TORNOZELO EM ESCOLARES PRATICANTES DE BASQUETEBOL

Tiberio Cesar Lima Bezerra

Brasília 


\title{
EFEITOS DE EXERCÍCIOS PROPRIOCEPTIVOS NO EQUILÍBRIO POSTURAL E NA ATIVIDADE ELETROMIOGRÁFICA DE EXTENSORES DO TORNOZELO EM ESCOLARES PRATICANTES DE BASQUETEBOL
}

TIBERIO CESAR LIMA BEZERRA

\begin{abstract}
Dissertação apresentada à
Faculdade de Educação Física da Universidade de Brasília, como requisito parcial para obtenção do grau de Mestre em Educação Física.
\end{abstract}




\section{EFEITOS DE EXERCÍCIOS PROPRIOCEPTIVOS NO EQUILÍBRIO POSTURAL E NA ATIVIDADE ELETROMIOGRÁFICA DE EXTENSORES DO TORNOZELO EM ESCOLARES PRATICANTES DE BASQUETEBOL}

Dissertação aprovada como requisito parcial para obtenção do título de Mestre em Educação Física pelo Programa de Pós Graduação da Faculdade de Educação Física da Universidade de Brasília.

Banca Examinadora:

Prof. Dr. Rinaldo André Mezzarane (Orientador - FEF/UnB)

Profa. Dr ${ }^{a}$ Ana Cristina de David.

(Examinador Interno - FEF/UnB)

Prof ${ }^{a}$. Dr ${ }^{a}$. Maria Gracinda dos Santos Alves

(Examinador Externo - Universidade Católica de Brasília)

Prof $^{a}$. Dra . Luciana Hagstrom Bex

(Examinador Suplente - FEF/UnB)

Brasília - DF, de de 2016 
Ao Basquetebol, ao RAP nacional e ao meu filho Augusto César, que salvaram minha vida mais de uma vez. Dedico 


\section{AGRADECIMENTOS}

Começo agradecendo a Deus, Buda, Jesus, Jeová, Zambi, Oxalá, Shiva, Tupã, Zeus, Odin, Ogun, ou qualquer outro nome que a humanidade tenha dado ao que eu acredito que seja uma força do universo que nós necessitamos nomear e que me ajudou a chegar até este momento, não facilitando as coisas e sim sempre me colocando com condições de exercer as tarefas que os obstáculos exigiam para cada etapa da minha vida, muito obrigado, tenho muito mais do que eu mereço.

Não posso de maneira alguma esquecer minha Mãe, Dona Neide, simplesmente eu amo você, tudo que eu tenho de bom na minha formação tem sua interferência, aprendi, às vezes com exemplos, às vezes com palavras, às vezes com as duas coisas, tenha certeza que tudo que passamos juntos, que estamos passando e vamos passar valeu e valerá a pena sempre, trabalho e esforço com o que temos de melhor será recompensado, esta é uma conquista nossa, pois não teria nem imaginado que um dia o sonho se tornaria realidade se no meu caminho não estivesse sua mão para me mostrar como o estudo e o trabalho valem a pena.

Agradecimento total ao meu filho Augusto César, esta criança que hoje tem 8 anos não faz ideia de como é importante na minha vida, inclusive para que eu esteja aqui escrevendo estas linhas de agradecimento nas madrugadas da vida enquanto ele dorme ao meu lado neste momento. A partir do dia que me tornei pai eu pude perceber que algumas coisas que eu acreditava não eram tão importantes, outras que eu não acreditava se tornaram muito valiosas e outras que eu nem sabia que existia se tornaram essenciais, meu mundo agora não gira em torno do Sol e sim em volta desta criança que eu amo mais que a minha própria vida, eu amo muito você meu filho, muito obrigado por tudo, você nem imagina o que já fez por mim, quem sabe um dia eu conto para você.

Não haveria nenhuma condição deste projeto ter se iniciado sem a competência, paciência, principalmente paciência, conhecimento, compromisso e dedicação do meu orientador Professor Doutor Rinaldo André Mezzarane, que acreditou em uma ideia, investiu tempo e conhecimento para podermos chegar até este momento, as mudanças que ocorreram, as idéias que surgiram 
e os momentos de trabalho árduo fizeram de mim uma pessoa melhor e um profissional mais preparado para os desafios futuros, muito obrigado, e tenha certeza, talvez eu não tenha feito o meu melhor, mas fiz o meu melhor possível no momento, agradecimento eterno pelo aprendizado como profissional e como pessoa, nos valores morais, éticos e humanos, você é uma inspiração pra mim.

Agradecimento super especial a Professora Doutora Ana Cristina que além de emprestar o equipamento para coleta dos dados, a Plataforma de Força AMTI, disponibilizou o laboratório que está sobre sua responsabilidade para que o estudo piloto pudesse ocorrer.

Sem citar nomes para não correr risco de cometer injustiças agradeço de forma profunda aos meus professores e professoras que me inspiraram desde o ensino primário até este momento em que estou prestes a terminar mais uma etapa de meus estudos, com exemplo no seu trabalho, com dedicação, respeito e compromisso em cada momento, mesmo com todas as dificuldades conhecidas na prática do magistério eu fui uma pessoa sortuda ou privilegiada, encontrei muito mais bons exemplos de professores do que o contrário, a todos vocês eu afirmo, sim, vale a pena se dedicar arduamente para tentar influenciar de maneira positiva na vida das pessoas que aparecem nas salas de aula, não importa se é no ensino infantil ou na pós graduação, sempre é necessário fazer o melhor possível, e tenho muitos que passaram na minha vida que me inspiraram como profissional, muito obrigado a todos.

Ao Professor Márcio Júnior, meu amigo a mais de 20 anos, que propiciou a realização desta pesquisa no momento em que aceitou que sua turma de atletas, que ele tanto cuida e ama, participasse deste estudo, nunca mediu esforços para que desse tudo certo, cedendo espaço, tempo nas suas atividades e material para que tudo acontecesse da melhor forma possível, mais que um amigo, um irmão e exemplo de profissional que ama o que faz, muito obrigado por tudo meu amigo, o basquete nos aproximou e este esporte é nossa vida profissional e que assim se mantenha por muito tempo.

Aos colegas de mestrado que sempre me incentivaram e me ajudaram no que fosse necessário e possível o agradecimento surge naturalmente nos sorrisos e abraços nos momentos que nos encontramos, e como sempre digo para vocês, contem comigo, precisando sabem como me encontrar, amizade, respeito e admiração não se compra, se conquista, estamos juntos sempre. 
As pessoas que ajudaram nas coletas Lari Gomes e Dani Coimbra, futuras pesquisadoras que a Educação Física terá a honra de ter trabalhando para melhorar ainda mais os conhecimentos sobre o corpo humano e o exercícios físico, e a Professora Doutora Luciana Bex, que sempre estiveram dispostas para ajudar com os voluntários na coleta pré e pós-intervenção.

Não tem como terminar de agradecer, tenho muito mais motivo para agradecer do que posso imaginar, sem citar as pessoas que trabalharam comigo e sempre me incentivaram a procurar realizar este sonho, Professora Doutora Amiga Irmã de Coração Cássia Hiragi, Professor Doutor Mário Bispo e Professora Doutora Maria Alice, suas palavras de incentivo tenho guardado no coração e na memória, para que eu sempre possa ter sentido nas minhas ações, muito obrigado do fundo do meu coração.

Para finalizar quero agradecer de forma profunda e intensa aos voluntários que participaram do estudo sem medir esforços, sempre realizando as tarefas propostas de maneira séria e dedicada, nos treinos chegando no horário, repondo falta, indo e vindo até a UnB para as coletas, saindo da escola, chegando para a escola, com provas e trabalhos escolares entre os treinos e coletas, mas sempre mostrando seriedade total no que foi proposto, vocês foram sensacionais, espero que a vinda até a FEF/UnB possa ter influenciado ou criado sonhos futuros. Lembrem se sempre, I (We) Love This Game, I (We) Believe I (We) CanFly e principalmente, For This I (We) Play, somos felizes por jogar e praticar o melhor esporte do universo, salve o Basquetebol. 
Você não sabe o quanto eu caminhei para chegar até aqui, percorri milhas e milhas...

(Cidade Negra) 


\section{SUMÁRIO}

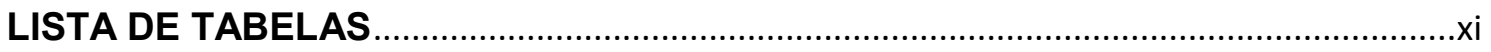

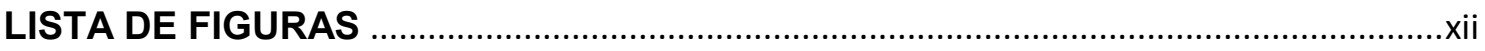

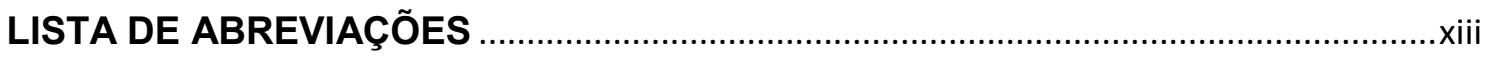

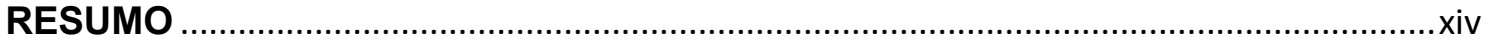

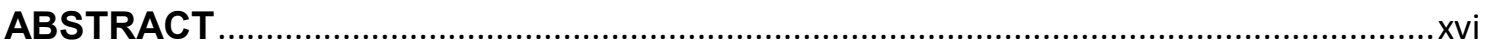

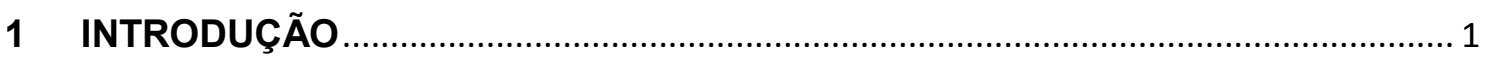

1.1 Treinamento Proprioceptivo e Controle Motor.............................................. 2

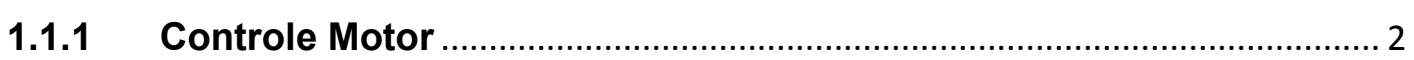

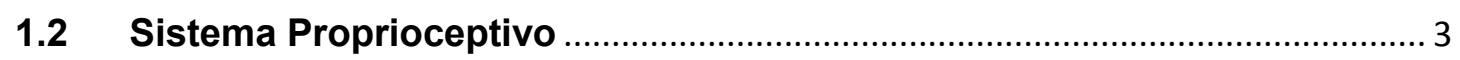

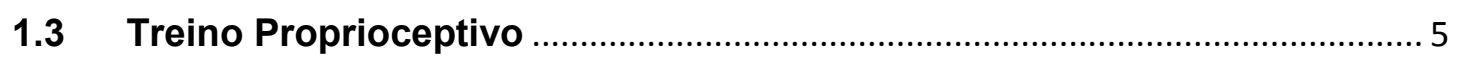

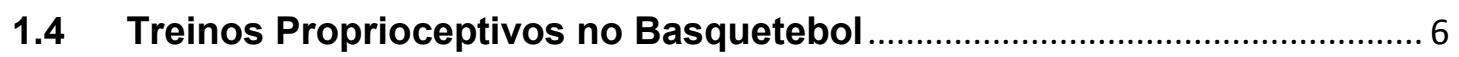

1.5 Desenvolvimento na faixa etária entre 12 e 16 anos .................................... 8

1.6 Estratégias de Controle Postural ............................................................... 11

1.7 Técnicas Biomecânicas Para o Estudo do Controle Postural .................... 12

1.8 Técnicas Eletrofisiológicas Para o Estudo do Controle Postural .............. 14

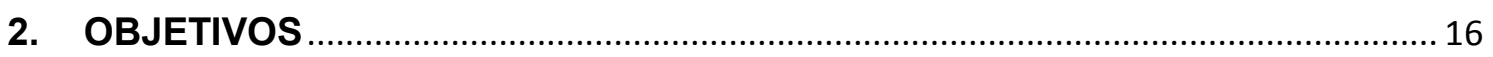

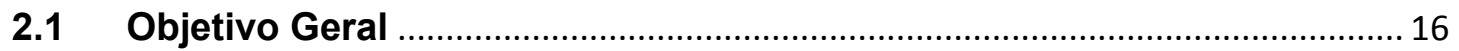

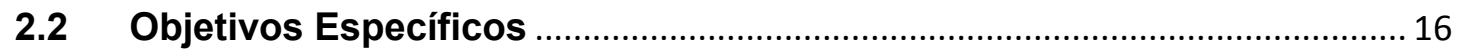

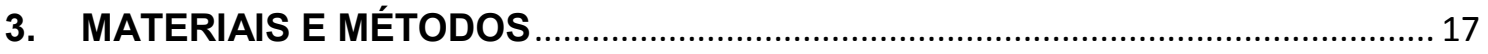

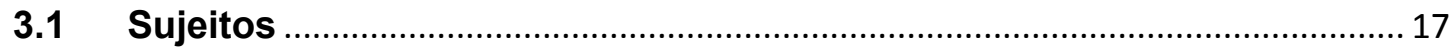

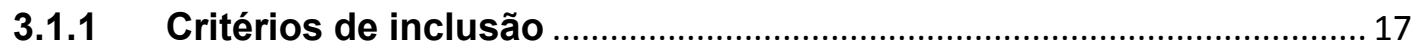

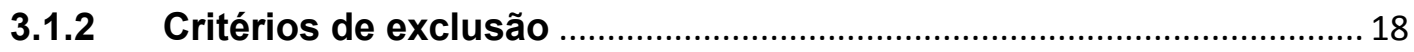

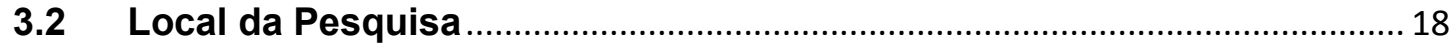

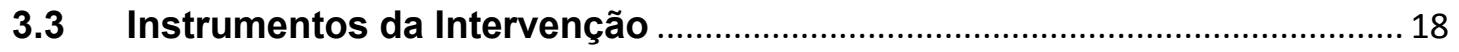

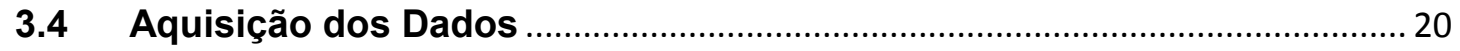

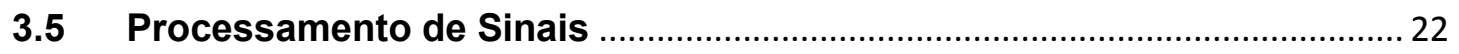

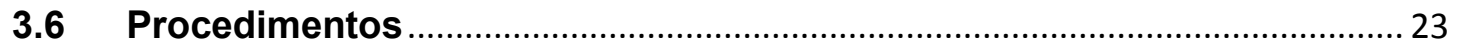

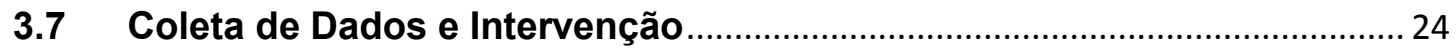

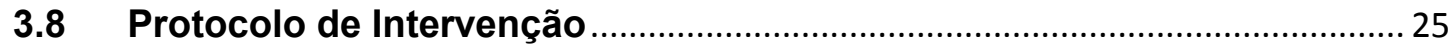

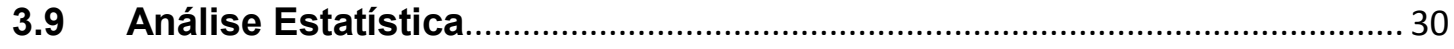

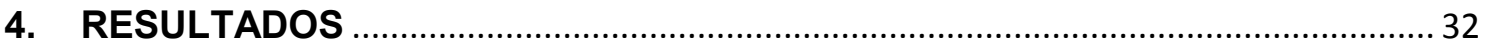

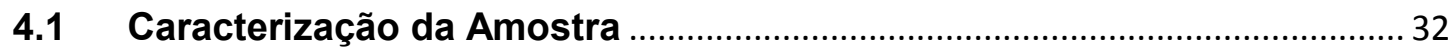


4.2 RMS do CP na Direção médio-lateral ............................................................ 34

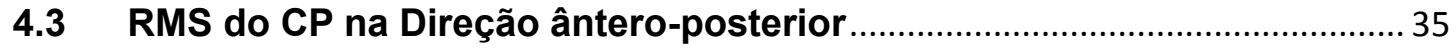

4.4 Velocidade Média do CP na Direção médio-lateral ......................................... 36

4.5 Velocidade Média do CP na Direção ântero-posterior ................................... 36

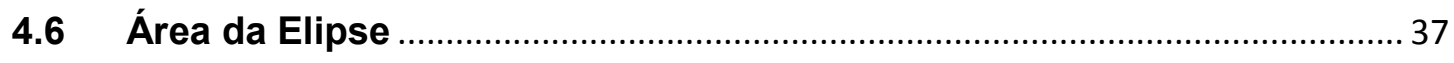

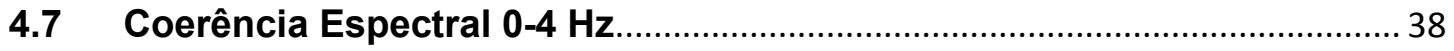

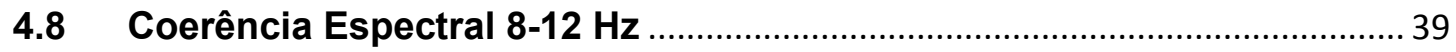

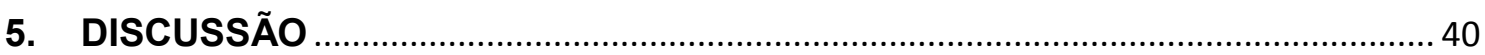

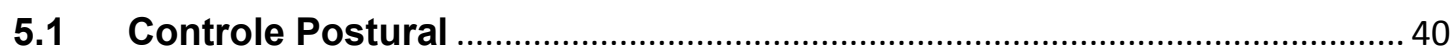

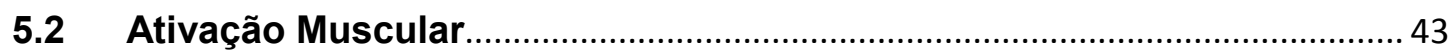

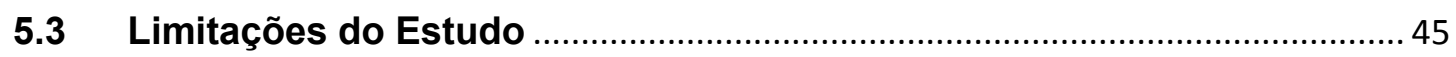

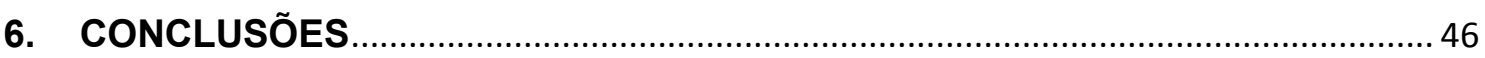

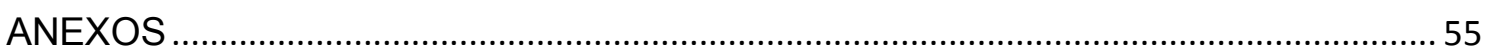

ANEXO A -Termo de Consentimento Livre e Esclarecido .................................................... 1

ANEXO B -Termo de Assentimento Livre e Esclarecido..................................................... 3

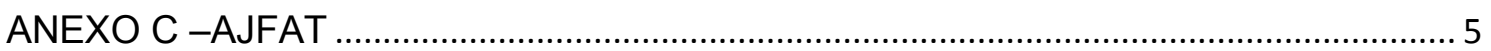

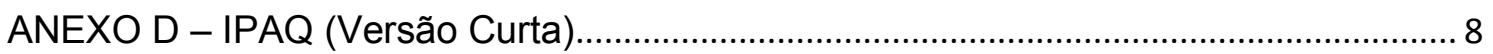

ANEXO E - QUESTIONÁRIO DE CARACTERIZAÇÃO .................................................. 11

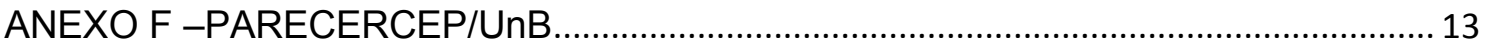




\section{LISTA DE TABELAS}

Tabela 1: Caracterização do GE e do GC Pré-intervenção

Tabela 2: Caracterização do GE e do GC Pós-intervenção 


\section{LISTA DE FIGURAS}

Figura 1.1: Esquema que representa os componentes do sistema proprioceptivo.

Figura 1.2: Curva de velocidade de desenvolvimento da estatura.

Figura 1.3: Esquema mostrando: a) um sujeito na postura ereta e b) as oscilações que ocorrem principalmente no sentido ântero-posterior. A seta em verde (e a letra ' $F$ ') representa a força de reação do solo. A linha vermelha indica a projeção do centro de massa no solo. À direita está representada uma plataforma de força utilizada para medir tais oscilações a partir as forças ( $F x$, $\mathrm{Fy}, \mathrm{e} \mathrm{Fz}$ ) e dos momentos (Mx, My e Mz) obtidos nos três eixos ortogonais.

Figura 3.1: Equipamentos utilizados no treinamento proprioceptivo.

Figura 3.2: Espuma de Alta Densidade sobre a plataforma de força AMTI.

Figura 3.3: Eletromiógrafo Delsys.

Figura 3.4: Aquisição do EMG com o Lab View 3.1.

Figura 3.5: Posicionamento do eletrodo terra de captação.

Figura 3.6: Linha do tempo representando o cronograma dos procedimentos de pesquisa.

Figura 3.7: Exercício grau um.

Figura 3.8: Exercício grau dois.

Figura 3.9: Exercício grau três.

Figura 3.10: Exercício grau quatro.

Figura 4.1: Sinais de um sujeito representativo mostrando no painel superior o $\mathrm{CP}$ _ap e no painel inferior a atividade eletromiográfica do soleus da perna direita.

Figura 4.2: Média dos valores da variável RMS $(\mathrm{em} \mathrm{cm})$ do $\mathrm{CP} \_\mathrm{ml}$ medido antes e após o período de treinamento do GC e GE.

Figura 4.3: Média dos valores da variável RMS $(\mathrm{em} \mathrm{cm})$ do CP_ap medido antes e após o período de treinamento do GC e GE.

Figura 4.4: Média dos valores da variável VM $(\mathrm{em} \mathrm{cm} / \mathrm{s})$ do $\mathrm{CP} \_\mathrm{ml}$ medido antes e após o período de treinamento do GC e GE.

Figura 4.5: Média dos valores da variável VM $(\mathrm{em} \mathrm{cm} / \mathrm{s})$ do $C P \_a p$ medido antes e após o período de treinamento do GC e GE. ( ${ }^{*} p<0,0 \overline{05}$ entre os momentos para o $\mathrm{GE}, \mathrm{\dagger p}<0,05$ entre os grupos para a diferença das médias). 
Figura 4.6: Média dos valores da variável área da elipse do CP medido antes e após o período de treinamento do GC e GE.

Figura 4.7: Média dos valores da variável coerência espectral frequência 0-4 $\mathrm{Hz}$ medido antes e após o período de treinamento do GC e GE.

Figura 4.8: Média dos valores da variável coerência espectral na faixa de frequência 8-12 Hz medido antes e após o período de treinamento do GC e GE ( ${ }^{*} p<0,05$ entre os momentos para o GE e para o GC). 


\section{LISTA DE ABREVIAÇÕES}

AJFAT -Ankle Joint Functional Assessment Tool

AMTI - Advanced Mechanical Technologies, Inc

CEMEIT - Centro de Ensino Médio Escola Industrial de Taguatinga

CEP/FS - Comitê de Ética e Pesquisa da Faculdade de Saúde

CG - Centro de Gravidade

CID - Centro de Iniciação Desportiva

CM - Centro de Massa

CP - Centro de Pressão

CP_ap - centro de pressão no sentido ântero-posterior

CP_ml - centro de pressão no sentido médio-lateral

DF - Distrito Federal

EMG -Eletromiograma

FEF - Faculdade de Educação Física

FFT -Fast Fourier Transform

GC -GrupoControle

GE - Grupo Experimental

IMC - índice de massa corporal

IPAQ - InternationalPhysicalActivityQuestionnaire

LCA - Ligamento Cruzado Anterior

MMII - Membros Inferiores

NFSHA-National Federation of State High School Associations

OTG - Órgão Tendinoso de Golgi

RMS -RootMean Square

SEEDF - Secretaria de Estado de Educação do Distrito Federal

SNC - Sistema Nervoso Central

TALE - Termo de Assentimento Livre e Esclarecido

TCLE - Termo de Consentimento Livre e Esclarecido

UnB - Universidade de Brasília

VM - Velocidade média 


\section{RESUMO}

\section{EFEITOS DE EXERCÍCIOS PROPRIOCEPTIVOS NO EQUILÍBRIO POSTURAL E NA ATIVIDADE ELETROMIOGRÁFICA DE EXTENSORES DO TORNOZELO EM ESCOLARES PRATICANTES DE BASQUETEBOL}

Autor: Tiberio Cesar Lima Bezerra

Orientador: Rinaldo André Mezzarane

A prática do basquetebol como atividade recreativa até $\mathrm{O}$ alto rendimento apresenta um número significativo de lesões, com maior incidência na articulação do tornozelo. Treinamentos que possam aprimorar o equilíbrio postural constituem uma alternativa interessante para os profissionais de educação física. Contudo, estudos que utilizam abordagens biomecânicas e eletrofisiológicas em conjunto para estudar as adaptações do sistema de controle postural após treinamentos de equilíbrio ainda são escassos. $O$ objetivo deste estudo é avaliar o efeito de um programa de exercícios proprioceptivos de 8 semanas sobre o equilíbrio postural e sobre a atividade muscular de extensores do tornozelo em escolares adolescentes praticantes de basquetebol. Foram recrutados 29 indivíduos do gênero masculino, com idades entre 13 e 16 anos, praticantes de basquetebol por pelo menos 1 ano. Os voluntários foram distribuídos aleatoriamente em dois grupos: 14 indivíduos no Grupo Experimental (GE) e 15 indivíduos no Grupo Controle (GC). O valor eficaz (Root Mean Square - RMS), a velocidade média (VM) e a área da elipse do estatocinesiograma foram calculados a partir dos dados do centro de pressão (CP) obtidos por meio de uma plataforma de força. A atividade do músculo soleus das duas pernas foi registrada utilizando-se eletromiografia de superfície. Para a coleta o indivíduo se manteve na postura ortostática quieta em dois momentos distintos: pré-intervenção e após 8 semanas de treinos de propriocepção (pós-intervenção). Os treinos foram realizados três vezes por semana antes do treino de basquetebol. As coletas ocorreram com os voluntários de olhos fechados sobre uma espuma de alta densidade. Os resultados apontaram diferenças significativas na VM após a intervenção no GE, e para ambos os grupos na coerência espectral entre os EMGs dos músculos soleus de ambas as pernas na faixa de $8-12 \mathrm{~Hz}$ (não havendo efeito 
na faixa de 0-4 Hz). Sugere-se que treinos proprioceptivos alteram as componentes rápidas do controle postural.

Palavras-chave: Propriocepção, plataforma de força, adolescentes, eletromiografia, coerência espectral. 


\section{ABSTRACT \\ EFFECTS OF PORPRIOCEPTIVE TRAINING ON BOTH BALANCE AND ELECTROMYOGRAPHIC ACTIVITY OF ANKLE EXTENSORS IN YOUNG BASKETBALL PLAYERS}

\section{Author: Tiberio Cesar Lima Bezerra \\ Advicer: Rinaldo André Mezzarane}

The practice of basketball induces a significant number of injuries, with higher incidence in the ankle joint. Trainings that can promote postural balance constitute an interesting alternative for the physical education professionals. However, estudies that use biomechanical and electrophysiological approaches to investigate the adaptations in the postural control system followed physical training are scarce. The aim of this study is to evaluate the effect of a 8 weeks exercise program on both postural balance and muscle activity of ankle extensors in Young basketball players. The volunteers were 29 basketball players (age between 13 and 16 years old) that practice the Sport for at least 1 year. They were randomly divided in two groups: 14 in the experimental group (EG) and 15 in the control group (CG). The Root Mean Square (RMS), mean velocity (MV) and the area of the ellipse (that encompasses $85 \%$ of the center of pressure values) were calculated from the data of the center of pressure (CP) obtained by means of a force platform. The soleus muscle activity of the two legs was recorded using surface electromyography. The participants remained in up right posture over a foam with eyes closed in two distinct moments, préintervention and after 8 weeks with próprio ceptive training (post-intervention). The trainings were held three times a week, before the basketball trainning. The results showed significant reduction in MV values for EG followed the 8 weeks of intervention. Spectral coherence between EMG of both soleus muscles (from both legs) in the range of $8-12 \mathrm{~Hz}$ was significant for the two groups (no significant diferences for $0-4 \mathrm{~Hz}$ was found). It seems that the proprioceptive training mainlya effects the fast components of postural control.

Keywords: Proprioception, force platform, teenagers, electromyography, spectral coherence. 


\section{INTRODUÇÃO}

O basquetebol é uma das modalidades esportivas mais praticadas no mundo, a National Federation of State High School Associations (NFSHA, 2005), que reúne as equipes nacionais de estudantes entre 14 a 18 anos registrou 1,8 milhões de praticantes na temporada 2004/2005 somente nos Estados Unidos.

A participação neste esporte de maneira recreativa até 0 alto rendimento expõe os praticantes a momentos críticos que podem ser mais suscetíveis a lesões, como por exemplo, a aterrissagem em bandejas e rebotes, mudanças bruscas de velocidade e direção ou mesmo a manutenção da posição do "pé de apoio", também conhecido como "pé de pivô".

POWELL \& BARBER-FOSS (1999) levantaram dados sobre lesões em estudantes do gênero masculino, adolescentes e praticantes de várias modalidades esportivas e constatou que no basquetebol a incidência de lesões articulares é algo em torno de $23 \%$. Destas, $65 \%$ são nas articulações dos membros inferiores (MMII), quadril, joelho e tornozelo, sendo a articulação do tornozelo a mais suscetível a lesão.

BEARD et al. (1993) afirmam que a propriocepção é importante na reabilitação e prevenção de lesões no tornozelo. $O$ treino proprioceptivo pode alterar o controle postural em situações estáticas e dinâmicas e assim talvez diminuir a incidência destas lesões, principalmente na articulação do tornozelo, que está mais suscetível a sofrer torção por inversão.

Dada a prevalência de lesões na articulação do tornozelo no basquetebol e o papel dos flexores e extensores desta articulação no controle da postura, uma questão que surge é se a atividade muscular e a oscilação postural em situações de instabilidade podem ser alteradas após um treinamento proprioceptivo. Possíveis mudanças em parâmetros posturográficos poderiam indicar uma adaptação do sistema de controle postural.

O controle da postura ortostática é uma tarefa motora fundamental, pois por meio dela outras atividades motoras são passíveis de serem realizadas. Para tanto, o sistema de controle postural visa a manter a projeção do Centro de Gravidade (CG) dentro da área da base de apoio.Os sistemas visual, vestibular e proprioceptivo têm participação fundamental nesta função. 
As variáveis ora utilizadas para observar mudanças no controle postural são o valor eficaz (Root Mean Square - RMS), que fornece informações sobre a variabilidade do deslocamento do Centro de Pressão (CP), a velocidade média (VM) do CP, e a área da elipse formada pelo caminho percorrido pelo CP.

Estas variáveis, calculadas a partir dos dados obtidos de uma plataforma de força, são frequentemente utilizadas na avaliação da estabilidade postural (RUGELJ \& SEVSEK, 2007).

O treinamento proprioceptivo pode alterar algumas variáveis do controle postural. Por exemplo, exercícios proprioceptivos podem melhorar a capacidade somatossensorial resultando num melhor desempenho no equilíbrio postural (MAJLESI et al., 2014).

Deficiências no sistema somatossensorial podem ser melhoradas por meio de exercícios proprioceptivos que ajudam a aumentar o tempo de reação e os padrões de contração muscular que favorecem a correção de inversão excessiva (BOCCOLINI et al., 2013).

HOLM et al. (2004) afirmam que alguns programas de treinamentos proprioceptivos são projetados para melhorar a função muscular (padrões de recrutamento e tempo de reação) e aumentar o controle neuromuscular.

Tendo em vista este cenário de relação entre treinos proprioceptivos e controle postural, este estudo se propõe a responder a seguinte pergunta: um programa de treinamento proprioceptivo, de oito semanas e com vinte e quatro sessões, é capaz de promover alterações no controle postural e no padrão de ativação muscular de extensores de tornozelo de escolares adolescentes praticantes de basquetebol?

\subsection{Treinamento Proprioceptivo e Controle Motor}

\subsubsection{Controle Motor}

Pode-se dizer que o controle motor é o processo pelo qual o sistema nervoso central (SNC) coordena os músculos e membros envolvidos no desempenho de uma habilidade motora, ou seja, é a integração das informações sensoriais sobre o ambiente no qual o indivíduo está inserido e o estado atual do corpo.Estas informações são utilizadas para determinar o 
conjunto apropriado de forças musculares e ativações conjuntas e gerar a ação desejada.

Este processo requer a interação entre o SNC e o sistema musculoesquelético. Um controle motor bem executado é crucial para interagir com o mundo, não só para determinar as capacidades de ação, mas para a regulação do equilíbrio e estabilidade do corpo. (ROSENBAUM, 2011).

LATASH et al. (2012) afirmam que o tempo de reação de tarefas simples pode ser usado para revelar informações sobre diferentes etapas de planejamento. Este tempo refere-se ao período entre a apresentação do estímulo e o fim do tempo de resposta do movimento, ou seja, o tempo que demora em completar o movimento.

As primeiras experiências de tempo de reação foram realizadas por Franciscus Donders, ele utilizava a diferença em tempos de resposta a uma tarefa de reação simples e uma tarefa de reação escolhida para determinar o período de tempo necessário para processar os estímulos e escolher a resposta correta.

Esta abordagem deu origem à ideia de que o tempo de reação era constituído pela identificação de um estímulo seguido de uma seleção de resposta que leva a um movimento correto.

Outras pesquisas evidenciaram que esses estágios não existem, mas que o período de seleção de resposta de qualquer tempo de reação aumenta à medida que os números de opções disponíveis crescem, uma relação conhecida como lei de Hick. (LATASH et al., 2012)

\subsection{Sistema Proprioceptivo}

Uma das principais fontes de informação para o controle motor vem de estruturas como: os fusos neuromusculares que detectam o estiramento do músculo, do Órgão Tendinoso de Golgi (OTG), presente nos tendões e informam o SNC sobre a tensão muscular, e os receptores articulares que informam o SNC, sobre a posição e velocidade angular, como ilustrado na Figura 1.1. 


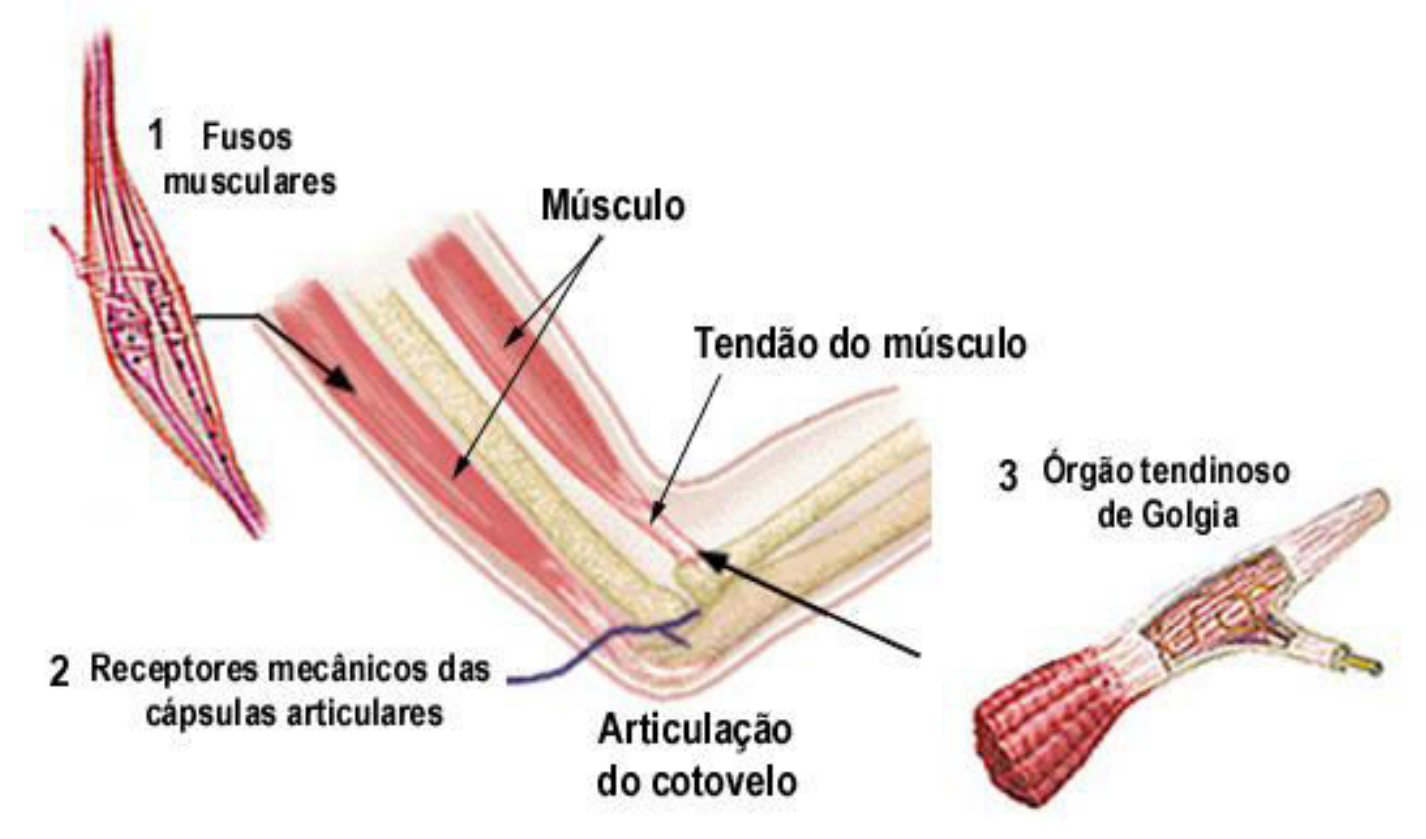

Figura 1.1: Esquema que representa os componentes do sistema proprioceptivo. Fonte: http://www.ibb.unesp.br

PURVES et al. (2001) afirmam que a sensação é a capacidade de perceber, traduzir e codificar informações geradas por estímulos decorrentes tanto do ambiente externo quanto do interno, o cérebro tem regiões dedicadas a esse processo.

WINTER (1995) afirma que o sistema somatosensorial, proporciona uma representação corporal estática e dinâmica, fornecendo dados ao SNC sobre a inter-relação de diferentes segmentos do corpo. COHEN \& ABDALLA (2005) afirmam que o sistema somatosensorial em uma condição estática proporciona orientação consciente do corpo, e em uma situação dinâmica informa o SNC sobre à quantidade e direção do movimento.

Os mecanorreceptores cutâneos fornecem informações provenientes dos estímulos externos, outra importante classe de receptores que fornece informações sobre forças mecânicas decorrentes do próprio corpo, o sistema músculo-esquelético em particular. Estes são chamados de proprioceptores, que se destina principalmente dar informações detalhadas e contínuas sobre a posição dos membros e outras partes do corpo no espaço.

Mecanorreceptores, incluindo fusos musculares, OTGs e os receptores comuns, fornecem este tipo de informação sensorial, que é essencial para o desempenho de precisão de movimentos complexos. Informações sobre a 
posição e o movimento da cabeça são particularmente importantes; Neste caso, proprioceptores são integrados com o sistema vestibular altamente especializado.

\subsection{Treino Proprioceptivo}

A propriocepção é um conjunto de reações que resultam num input neural cumulativo ao SNC, de mecanoreceptores nas articulações, ligamentos, músculos, tendões e pele, é a sensação de movimento (cinestesia) e posição articular (senso posicional) articulares de fontes diferentes do sistema sensoriomotor (cutânea, visual, e auditiva) (RIEMANN \& LEPHART, 2002).

O treino proprioceptivo visa estimular os elementos que formam a propriocepção para que se otimizem as respostas neurais e musculares do indivíduo, fator que compõe o controle postural do ser humano, este tipo de treino parece resultar numa mudança de domínio visual para o proprioceptivo na regulação do controle postural (COLLET, 2004).

O treino proprioceptivo é utilizado desde a reabilitação pós-cirúrgica até em treinos de atletas de alto rendimento, diferenciado pela intensidade e volume para cada objetivo e situação. SHIM et al. (2015) sugerem que treinos proprioceptivos com duração entre quatro a oito sessões são para reabilitação do sistema proprioceptivo em situações de pós-operatório e treinos de oito a vinte sessões para a otimização do sistema proprioceptivo em sujeitos sem limitações funcionais na articulação. MARTINEZ-AMAT et al. (2013) sugerem que a frequência de sessões por semana seja no mínimo duas e no máximo três para que o treino proprioceptivo tenha o efeito desejado.

No trabalho desenvolvido por EILS \& ROSENBAUM (2001), que analisou a influência de um programa de treinamento proprioceptivo no controle postural de pacientes com instabilidade crônica de tornozelo, os autores demonstraram uma diminuição na oscilação do CP nas duas direções (médiolateral e ântero-posterior) e no tempo de reação muscular após seis semanas de intervenção com treinos proprioceptivos.

\subsection{Treinos Proprioceptivos no Basquetebol}

Informações proprioceptivas são necessárias para o controle neuromuscular da postura, aumentando assim a estabilidade articular funcional 
(RIEMANN \& LEPHART, 2002). Com isto, é possível obter uma maior proteção para as articulações, em especial a do tornozelo, por meio de diferentes tipos de exercícios proprioceptivos. Estes exercícios podem ser introduzidos no treinamento com vistas a amenizar ou diminuir a incidência de lesões, como é o caso das entorses (STEEN et al., 2004). Por exemplo, exercícios proprioceptivos prescritos para atletas jovens praticantes de basquetebol, com idade entre quatorze e dezesseis anos, promoveram uma redução na incidência de lesões no tornozelo durante os movimentos de bandeja e rebote ao longo de uma temporada inteira de treinos e jogos (HUBSHER et al., 2010).

Nota-se que, historicamente, os exercícios proprioceptivos têm sido utilizados nos treinos para evitar lesões em praticantes de várias modalidades esportivas (PARKKARI et al., 2011). Os exercícios proprioceptivos para atletas profissionais ou praticantes amadores de uma determinada modalidade esportiva devem ser adaptados para gestos executados durante o jogo ou prova (PARKKARI et al., 2011). Deste modo, o atleta tem condições de simular situações de jogo em condições desafiadoras nos treinos, para que assim possa ter uma resposta eficiente durante a partida.

De fato, tem-se observado que a inclusão de exercícios para a melhora do equilíbrio e do controle postural aumenta a estabilidade articular (MANDELBAUM et al., 2005). O número de lesões no tornozelo tem sido reduzido por meio do treinamento proprioceptivo também para praticantes de futebol e outras modalidades esportivas (ENGEBRESTSEN et al., 2009).

Quando o treino proprioceptivo foi implementado durante a temporada de competições de uma equipe de basquetebol, a ocorrência de lesão no tornozelo foi reduzida em 38\% (BOCCOLINI et al., 2013). Este tipo de treinamento mostrou-se eficiente também para diminuir o risco de entorse de tornozelo em atletas adolescentes (McLEOD, 2008; HERMAN et al., 2012).

Para um treino que tenha como objetivo a diminuição na incidência de lesões em atletas ou praticantes de basquetebol, criar instabilidades em movimentos que simulam situações de jogo é uma alternativa interessante, principalmente em uma articulação como o tornozelo.

Assim, o atleta terá uma resposta mais eficiente, garantindo um maior sinergismo muscular em alguma situação de instabilidade durante uma partida de basquetebol. Profissionais de educação física, sejam professores de 
equipes escolares ou técnicos de equipes de competição de alto rendimento, devem ter domínio sobre os tipos de treinamento que possam melhorar o controle postural e o equilíbrio em praticantes de basquetebol.

Um programa de treinamento proprioceptivo para pacientes com instabilidade crônica de tornozelo, mostrou uma diminuição na oscilação do CP e no tempo de reação muscular após seis semanas de intervenção. (EILS \& ROSENBAUM, 2001).

Em outro estudo foram comparados dois protocolos de treinos, com bola para alongamento e outro com treinos proprioceptivos, por um período de 6 semanas (LEE et al., 2014). Os resultados mostraram uma alteração na modulação da atividade dos músculos das costas no grupo que praticou os exercícios proprioceptivos, com a consequente diminuição de dor.

Compreender as variáveis que interferem no equilíbrio, e dedicar uma parte do treinamento esportivo do basquetebol para o desenvolvimento desta aptidão humana, pode ser uma alternativa para que a saúde física dos praticantes esteja preservada por uma longa temporada de jogos e treinos.

Avaliações do efeito do treinamento proprioceptivo sobre controle motor têm sido conduzidas utilizando variáveis biomecânicas (LEE et al., 2014) ou variáveis eletrofisiológicas (TAUBE et al., 2007). A diferença entre o presente trabalho e a grande maioria dos trabalhos da literatura, reside no fato de se realizar um estudo multivariável, conjugando abordagens biomecânicas e eletrofisiológicas.

\subsection{Desenvolvimento na faixa etária entre 12 e 16 anos}

COLEMAN \& ROKER (2013) explicam que o jovem que tem entre 12 e 16 anos de idade se encontra na fase da adolescência, esta fase é considerada de transição no desenvolvimento físico e psicológico humano, o jovem passa do período de puberdade para a idade adulta.

Durante esta fase os indivíduos podem sofrer alterações no controle postural devido ao crescimento da estatura e aumento acentuado da massa muscular nos meninos. Na fase de crescimento entre os 12 e 16 anos ocorre um rápido crescimento físico e alterações psicológicas, o início médio da puberdade é entre 11 a 12 anos para os meninos. Esta fase é influenciada principalmente pela hereditariedade apesar de fatores ambientais, como dieta e 
exercício, gerarem algumas influências. Estes fatores podem também contribuir para uma puberdade precoce ou tardia.

Alguns pontos mais significativos de desenvolvimento que podem influenciar o crescimento entre os 12 e 16 anos envolvem mudanças fisiológicas distintas de estatura, massa corporal, composição corporal e sistemas circulatórios e respiratórios. Estas mudanças são em grande parte influenciadas pelas atividades hormonais. Vale lembrar que os hormônios desempenham um papel organizacional no desenvolvimento dos jovens da faixa etária dos 12 aos 16 anos, preparando o corpo para a vida adulta. Devido às mudanças durante este período da vida ocorrem adaptações de todo o sistema motor para a manutenção do equilíbrio.

SMETANA (2013) com base na curva de velocidade de crescimento expressa pela idade, conclui que ocorre um intenso crescimento do esqueleto chamado de estirão puberal. A curva de velocidade de crescimento evidencia claramente ganhos de estatura no tempo em função da idade, desta forma, pode-se dizer então que o crescimento físico dos jovens de 12 a 16 anos no adolescente apresenta grande aquisição pôndero-estatural, ganhando cerca de $50 \%$ de sua massa corporal na idade adulta e $20 \%$ de sua estatura final, como mostra a Figura 1.2.

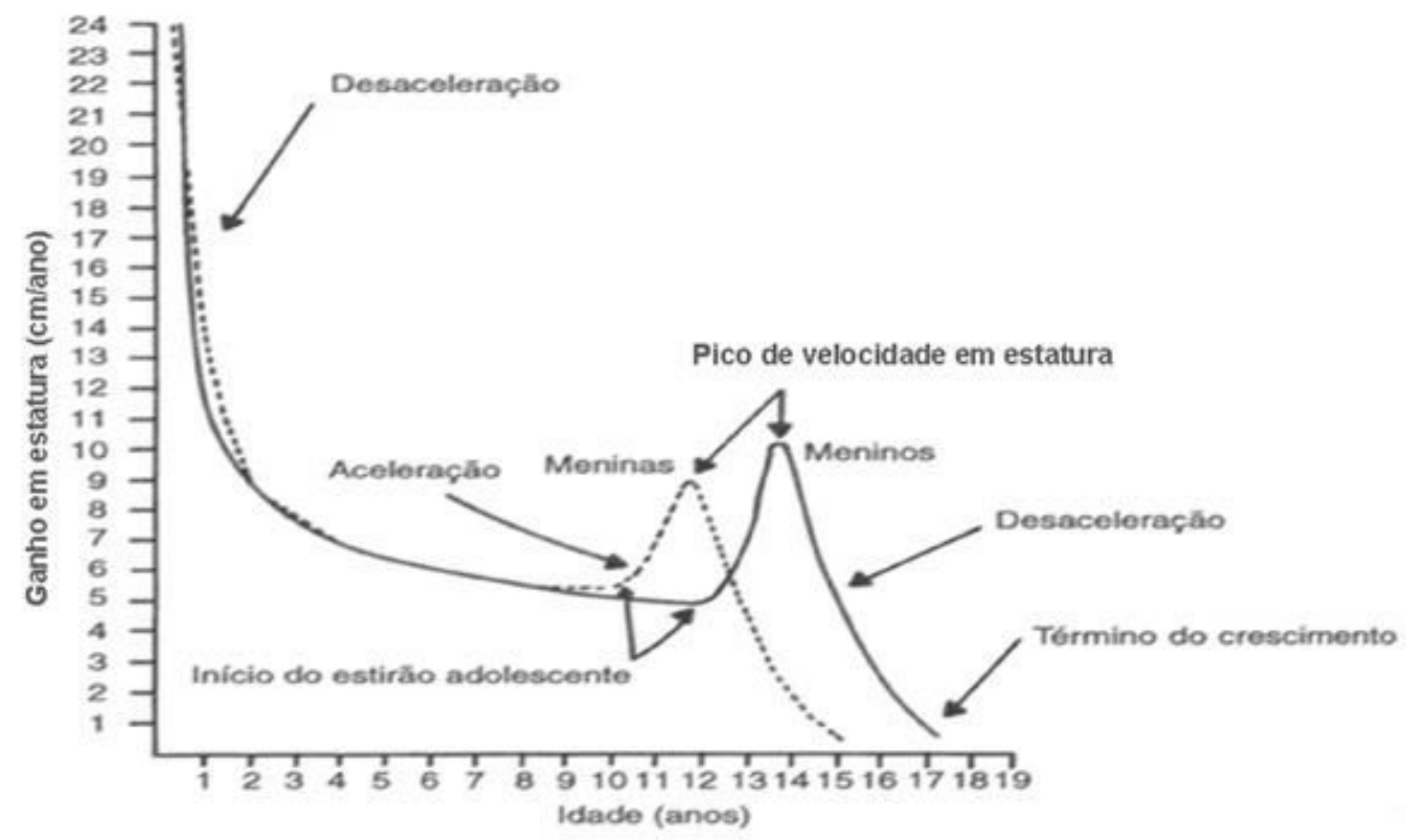

Figura 1.2: Curva de velocidade de desenvolvimento da estatura.

Fonte: RÉ (2011) 
Ressalta-se que o crescimento esquelético ocorrerá de forma não-linear, com velocidades variáveis de acordo com a fase da vida sendo influenciado por diversos fatores, entre eles, oferta alimentar, aspectos psicossociais e ambientais, bem como à ação hormonal predominante em cada fase.

Esta faixa etária, entre 13 e 16 anos, é considerada como uma fase de grande vulnerabilidade ao desenvolvimento humano e os fatores ambientais podem causar prejuízos irreparáveis ao desenvolvimento do jovem.

Ações preventivas de saúde, e uma atenção especial em relação à apresentação de doenças crônicas, transtornos alimentares, prática de exercícios físicos regulares e distúrbios nutricionais são necessárias.

A prática de exercício físico orientado, como o basquetebol, pode amenizar estes problemas, desde que se tenha um programa de atividades que possa desenvolver o indivíduo nas suas várias características, físicas, motoras, psicológicas, sociais, cognitivas entre outras.

O estirão puberal não ocorrerá de maneira uniforme, se iniciará pelos membros, seguindo uma direção distal-proximal, ou seja, pés e mãos, inicialmente, seguindo-se pernas e membros superiores, conferindo ao corpo do adolescente um aspecto desarmônico ou de desproporcionalidade, que volta a ser harmônico e proporcional ao término do estirão, se não ocorrer nenhum problema durante esta fase da vida, após o crescimento do tronco, principal responsável pela estatura final do indivíduo e por seu controle postural.

SAITO et al. (2011) afirmam que a composição corporal dos jovens da faixa etária de 13 a 16 anos oscila em função da maturação sexual influenciando o controle postural.

Por fim, a exceção ocorre com o tecido linfóide, ele apresentará um retardo progressivo na faixa etária dos 13 aos 16 anos, bem como do tecido nervoso que já estará com o seu crescimento estabelecido. Pode-se dizer que todos os órgãos e sistemas, entre eles o sistema cardiocirculatório e o sistema respiratório se desenvolvem durante esta a faixa etária de 13 a 16 anos.

Com isto ocorre um aumento da capacidade física, principalmente nos meninos, advindo do desenvolvimento do sistema cardiorrespiratório e das alterações hematológicas, aumento da eritropoiese, e do aumento da massa 
muscular que propicia um aumento da força e da resistência física. (SAITO et al., 2011)

Estas mudanças acentuadas que ocorrem na faixa etária da amostra utilizada no presente estudo (13 a 16 anos), podem influenciar nos resultados entre os momentos pré e pós-intervenção, mesmo sendo apenas oito semanas de diferença entre o início e o fim da intervenção com o treino proprioceptivo nos sujeitos que fazem parte do GE.

O aumento significativo da estatura, da massa muscular, a mudança no percentual de gordura neste momento da vida, pode alterar os valores em variáveis como RMS, VM e área da elipse devido a mudança de posição do CG e do CM.

\subsection{Estratégias de Controle Postural}

A definição de equilíbrio se relaciona com a capacidade do indivíduo em manter a projeção do CG dentro da área da base de apoio, formado, quando o indivíduo está na posição em pé, pelos limites externos dos pés quando na posição em pé (DUARTE \& FREITAS, 2010).

A postura estável, seja em situações de equilíbrio estático ou dinâmico, é a habilidade em manter o controle postural (PALMIERI et al., 2002). Partindo de uma análise mecânica, entende-se que um corpo está em equilíbrio estático quando a soma das forças e momentos que agem sobre ele tem como resultado zero, e como conseqüência se anulam (HSU et al., 2009).

Existem dois tipos de forças que agem sobre o corpo humano, são classificadas em externas, como por exemplo, a força gravitacional e internas, exemplo dos batimentos cardíacos (DUARTE \& FREITAS, 2010). Assim, no corpo humano, o termo mais adequado para definir uma situação de equilíbrio estático sobre a base de apoio é o equilíbrio quase-estático, uma vez que os sujeitos estão submetidos à aceleração da força gravitacional e da ativação muscular devido aos batimentos cardíacos e da respiração, o que causa pequenos desequilíbrios e gera a necessidade de se corrigir essa oscilação para a manutenção da postura (HSU et al., 2009).

Diante disto, se o corpo não for capaz de manter o CG sobre a base de apoio, ou seja, se ocorrer movimento do centro de massa (CM) para fora dos 
limites da base de apoio, ocorrerá a perda de equilíbrio e consequentemente quedas (POLLOCK et al., 2000).

A ação de manter o controle postural é um fator primordial na execução das atividades da vida cotidiana e para o desenvolvimento individual, e tem uma importância especial, visto que é a habilidade motora primária para as demais habilidades fundamentais.Um bom desenvolvimento do equilíbrio irá permitir a aquisição de um maior e mais qualificado repertório motor (BROGREN et al., 1988).

Embora para indivíduos saudáveis o controle do equilíbrio postural pareça uma tarefa simples na verdade consiste em um mecanismo complexo (FERDJALLAH M et al., 2002).

Manter o equilíbrio envolve interações minuciosas entre uma rede multissensorial constituída dos sistemas visual, vestibular e somatossensorial. Essa rede é comandada pelo SNC e executada pelo sistema musculoesquelético. Além disso, esses sistemas ainda estão aliados às experiências e influências do meio ambiente no qual o indivíduo está inserido (HADDERS-ALGRA, 2005; OLIVEIRA et al., 2008).

Então, para o sujeito manter-se em equilíbrio uma gama de ações ocorrem de forma integrada e simultânea, o que exige uma grande capacidade coordenativa e de comunicação desses sistemas, ocorrendo uma integração complexa entre sistema neural e musculoesquelético (HSU et al., 2009).

Os sistemas sensoriais informam de maneira contínua o SNC a posição e a trajetória do corpo no espaço. As informações advindas dos sistemas visual, somatossensitivo e vestibular estão disponíveis para detectar o movimento e a posição do corpo no espaço em relação à força gravitacional (HADDERS-ALGRA, 2005) desta forma cada um deles fornece uma diferente estrutura de referência para o controle postural (HORAK, 2006).

Para a manutenção da postura a atividade dos músculos da articulação do tornozelo se iniciam primeiro e então irradiada em seqüência à coxa e depois aos músculos do tronco (HORAK \& NASHNER, 1986). Este padrão de ativação exercida de torques compensatórios sobre a articulação do tornozelo tenta restaurar o equilíbrio, movendo o corpo e o centro de massa para a frente ou para trás. Este padrão foi designada como a estratégia de tornozelo porque 
desta forma restaura o equilíbrio, movendo o corpo, principalmente ao redor das articulações do tornozelo.

Para manter o equilíbrio com êxito ocorre a ativação da perna e do tronco, músculos em latências semelhantes, mas com organização e atividade diferente, os músculos antagônicos do tronco e da coxa aos usados no tornozelo (HORAK \& NASHNER, 1986).

Esta estratégia ativa o músculo de forma proximal para a parte distal, considerando que os músculos do tornozelo geralmente não respondem essa ativação padrão, produzindo assim um compensatório de força de cisalhamento horizontal contra a superfície de apoio. Mas pouco, se houver, torque de tornozelo este padrão tem sido denominado como a estratégia de quadril para manter o controle postural, porque o movimento resultante é focado principalmente sobre as articulações do quadril (HORAK \& NASHNER, 1986).

As perturbações em pé nas superfícies de apoio geram movimentos posturais mais complexos e ativam músculos associados com padrões de integração muscular entre as articulações do tornozelo e de quadril (HORAK \& NASHNER, 1986). Combinando assim diferentes relações temporais dos músculos e articulações, estes complexos movimentos posturais foram executados com combinações de torque e forças de cisalhamento horizontal e movimentos de tornozelo e articulações do quadril.

\subsection{Técnicas Biomecânicas Para o Estudo do Controle Postural}

A posturografia consiste no registro de variáveis associadas à postura humana. Uma destas variáveis é obtida pela medição das oscilações da resultante das forças que atuam na superfície de suporte utilizando uma plataforma de força. Estas oscilações estão relacionadas diretamente com a atividade do sistema motor realizada para manter o equilíbrio (WINTER, 1995).

O CP representa o resultado da ação do sistema de controle postural e da força de gravidade (DUARTE \& FREITAS, 2010), costuma-se associar a excursão do CP à excursão da projeção do CG do indivíduo em sua base de apoio. Em outras palavras, a plataforma de força pode ser utilizada para medir as oscilações posturais na postura ereta quieta (DUARTE \& FREITAS, 2010; WINTER, 1995) (Figura 1.3). 


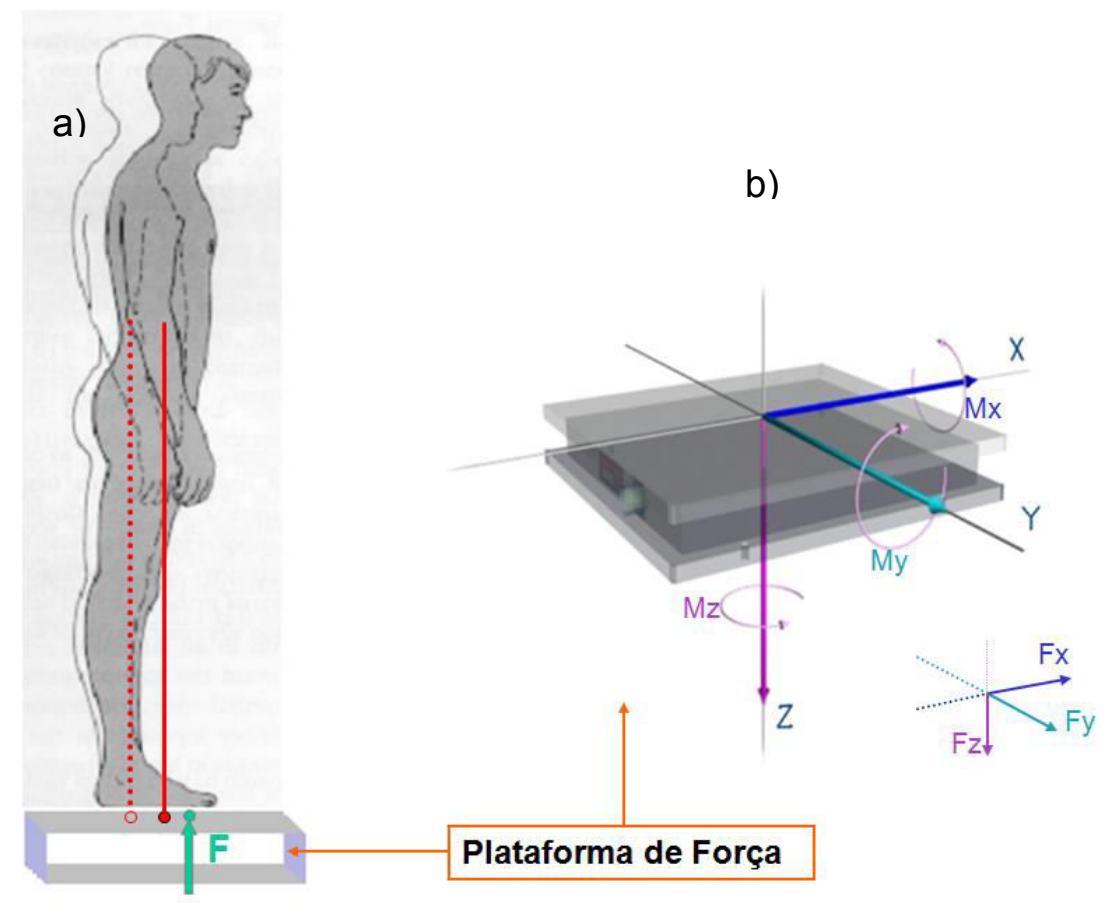

Figura 1.3: Esquema mostrando: a) um sujeito na postura ereta e b) as oscilações que ocorrem principalmente no sentido ântero-posterior. A seta em verde (e a letra 'F') representa a força de reação do solo. A linha vermelha indica a projeção do centro de massa no solo. À direita está representada uma plataforma de força utilizada para medir tais oscilações a partir as forças ( $F x, F y, e ~ F z)$ e dos momentos ( $M x, M y$ e $M z$ ) obtidos nos três eixos ortogonais.

Fonte: MEZZARANE, (2015)

O CP e a projeção do CG representam valores diferentes, pois o $\mathrm{CP}$ está relacionado à força de restauração do equilíbrio e reflete a aceleração do corpo, e a projeção do CG é uma medida de deslocamento (posição) e é totalmente independente da velocidade ou aceleração total do corpo ou de seus segmentos (WINTER, 1995).

O sinal do CP na direção ântero-posterior obtido na postura ereta quieta tem sido analisado com o intuito de extrair o máximo possível de informações sobre o controle postural realizado pelo SNC.

A estabilometria é a medida e o registro da contínua oscilação do corpo humano, esta técnica é realizada utilizando-se como instrumento as plataformas de força. Considerado um método preciso de medição por ser sensível em detectar pequenos deslocamentos (TEREKHOV, 1976).

Quando uma pessoa procura manter-se o mais estável possível na posição ereta quieta acontecem constantes oscilações. Essas oscilações ocorrem pela dificuldade em manter os segmentos corporais alinhados sobre uma base de suporte, mesmo que estável (BARELA, 2000). 
A variável mensurada nesse procedimento é o $C P$ que se refere ao resultado final das três componentes da reação do solo, ou seja, é o ponto de aplicação da resultante das forças verticais (sejam forças internas como a ação muscular, ou externas, como a gravidade) que agem na superfície de apoio (ORLIN \& McPOIL, 2000).

O deslocamento do ponto de aplicação dessas forças resulta em oscilações nas duas direções (médio-lateral e ântero-posterior), medidas pela plataforma de força (OLIVEIRA et al., 2000). Alguns parâmetros importantes para a avaliação do equilíbrio são a amplitude (valor eficaz do RMS) e área de deslocamento do CP (área da elipse), velocidade de deslocamento do CP (LIAO et al., 2003; SHUMWAY-COOK et al., 2003).

O corpo humano, com seu número relativamente grande de articulações, é um sistema instável do ponto de vista físico. A integração de sinais provenientes de diferentes canais sensoriais (visão, propriocepção, e sistema vestibular) permite um controle constante da manutenção do equilíbrio por parte do SNC.

\subsection{Técnicas Eletrofisiológicas Para o Estudo do Controle Postural}

A apresentação de condições desafiadoras para o equilíbrio corpóreo pode ajudar a revelar aspectos do controle postural que não se manifestam de maneira clara em medidas com o sujeito em situação de maior estabilidade.

Investigações acerca do padrão de ativação de músculos posturais, principalmente os extensores do tornozelo que são importantes para o controle da postura ortostática, já que controlam o torque do tornozelo para a manutenção do controle postural, podem prover dados relevantes que auxiliam no estudo de mecanismos neuronais atuantes no controle da postura (MEZZARANE \& KOHN, 2007; MEZZARANE \& KOHN, 2009). As ações destes mecanismos podem ser alteradas em resposta a treinos que estimulem a integração sensório-motora, induzindo uma melhora no desempenho motor devido à plasticidade do SNC.

Por exemplo, a coerência espectral entre sinais eletromiográficos obtidos bilateralmente permitirá aprofundar o conhecimento da modulação de neurônios envolvidos em ações coordenadas de ambas as pernas. Ou seja, a técnica de coerência espectral permite descrever a relação (ou o grau de 
correlação) entre dois sinais no domínio da frequência, e avaliar a possível existência de uma fonte comum para ambos. Esta fonte comum poderia ter origem em estruturas supra-segmentares (centros superiores do sistema nervoso) que influenciam o comportamento dos neurônios medulares atuantes no controle da postura. Espera-se que esta co-modulação da atividade muscular possa ser alterada após um programa de exercícios proprioceptivos.

Tem sido demonstrado que a coerência entre os eletromiogramas retificados, obtidos do músculo soleus de ambas as pernas durante a postura ortostática, foi significativa para duas regiões do espectro, $0 \mathrm{~Hz}$ à $4 \mathrm{~Hz}$ e $8 \mathrm{~Hz}$ à $12 \mathrm{~Hz}$ (BOONSTRA et al., 2008). A primeira região (frequências menores) está provavelmente relacionada às oscilações posturais, enquanto que a segunda região está relacionada à frequência de disparos de unidades motoras (GATEV et al., 1999; KOUZAKI \& MASANI 2012). BOONSTRA et al. (2008) mostraram que a informação visual pode alterar a coerência entre os eletromiogramas de ambos os músculos, sugerindo que a ação de vias descendentes (afetadas pela alteração no feedback sensorial) induz mudanças na organização do acoplamento bilateral entre os músculos extensores do tornozelo. Ainda não existem dados sobre essas alterações em decorrência da plasticidade neuronal após o treinamento proprioceptivo, mas espera-se que mecanismos responsáveis pela coordenação entre membros sejam otimizados após o treinamento.

O interesse do tipo de intervenção ora proposta (treinamento proprioceptivo) é a alegação de uma melhora no ganho proprioceptivo obtida após o treinamento, especialmente para a musculatura em torno da articulação do tornozelo. Esta melhora aumenta a eficiência da integração sensóriomotora, resultando em um controle mais preciso do equilíbrio. Desta forma, medidas eletrofisiológicas que refletem a ativação voluntária de músculos posturais, e de controle de oscilações posturais em resposta à ativação muscular, são altamente recomendáveis na avaliação das possíveis alterações em processos neuronais decorrentes do treinamento. 


\section{OBJETIVOS}

\subsection{Objetivo Geral}

Analisar o efeito de oito semanas de treinamento proprioceptivo no equilíbrio postural e na atividade eletromiográfica de extensores do tornozelo em escolares adolescentes praticantes de basquetebol.

\subsection{Objetivos Específicos}

A presente pesquisa tem como foco principal avaliar se 0 treinamento proprioceptivo altera o controle da postura ortostática em diferentes situações: na ausência de informação visual e na presença de informação proprioceptiva alterada devido a permanência sobre uma espuma de alta densidade. As variáveis a serem investigadas são o RMS e a VM extraídas da excursão do $\mathrm{CP}$ nas direções ântero-posterior e médio-lateral. Ainda será obtida a área da elipse (calculada por meio da análise das componentes principais a partir dos dados do estatocinesiograma) que encerra $85 \%$ dos valores do CP medido em ambas as direções.

Pretende-se também avaliar algumas componentes espectrais, coerência espectral na faixa de $0-4 \mathrm{~Hz}$ e de $8-12 \mathrm{~Hz}$, relevantes do eletromiograma (EMG) de superfície do músculo soleus, visando detectar possíveis alterações na modulação bilateral da atividade muscular de ambas as pernas (para algumas frequências de interesse) decorrentes do programa de treinamento proprioceptivo. Esta abordagem poderá melhorar o entendimento das alterações da modulação descendente bilateral de músculos posturais. 


\section{MATERIAIS E MÉTODOS}

\subsection{Sujeitos}

Para a realização deste estudo foram admitidos sujeitos que participam dos treinos do Centro de Iniciação Desportiva (CID) de Basquetebol do Centro de Ensino Médio Escola Industrial de Taguatinga (CEMEIT).

O CID é um programa da Secretaria de Estado de Educação do Distrito Federal (SEEDF) que tem como objetivo o desenvolvimento humano dos estudantes por meio da prática esportiva.Todos os professores envolvidos no CID são formados em Educação Física e desenvolvem trabalhos em várias modalidades esportivas.

Os treinos são no horário contrário de estudo dos participantes e as equipes são dividas por gênero e por faixa etária. Eles disputam campeonatos no Distrito Federal (DF), na região centro-oeste do país e em alguns casos competições nacionais e internacionais.

A amostra foi constituída por um grupo de 30 estudantes da equipe de basquetebol do CID do CEMEIT que treinavam em horário contrário ao da escola, alguns treinando no período matutino e outros treinando no período vespertino, sendo a amostra composta por voluntários que treinavam tanto no matutino quanto no vespertino.

Os sujeitos foram divididos em dois grupos, grupo experimental (GE) e grupo controle (GC) com 15 sujeitos em cada grupo. Esta divisão foi aleatorizada pelo programa MATLAB (Mathworks v.2014).

Um sujeito que fazia parte do GE desistiu da prática do basquetebol abandonando o treino e a pesquisa por problemas de saúde, deixando o GE com 14 voluntários.

\subsubsection{Critérios de inclusão}

- Não ter histórico de lesão nas articulações dos membros inferiores nos seis meses antecedentes do início da pesquisa;

- Ser do gênero masculino;

- Ter entre 13 e 16 anos de idade;

- Entregar o Termo de Consentimento Livre e Esclarecido (TCLE) assinado pelo responsável e pelo voluntário (ANEXO A). 
- Entregar o Termo de Assentimento Livre e Esclarecido (TALE) assinado pelo responsável com todas as informações referentes aos procedimentos da pesquisa, riscos, benefícios, objetivos e contatos dos pesquisadores (ANEXO B).

\subsubsection{Critérios de exclusão}

- Estudantes que tenham ficado sem participar das atividades do CID no ano de 2015 por qualquer motivo;

- Não participar de todas as sessões de treinos proprioceptivos durante 0 experimento;

- Sofrer alguma lesão nas articulações do membro inferior durante o período do estudo.

\subsection{Local da Pesquisa}

As coletas de dados pré e pós-intervenção ocorreram na Faculdade de Educação Física (FEF) da Universidade de Brasília (UnB) no Laboratório de Processamento Digital de Sinais Biológicos e Controle Motor, a coleta das características físicas como estatura, massa corporal, dobras cutâneas e os treinos de propriocepção ocorreram no CEMEIT antes do treino de basquete, o preenchimento dos questionários foram realizados também no CEMEIT nos dias de treinos podendo ser antes ou depois dos treinos de basquetebol.

\subsection{Instrumentos da Intervenção}

Todos os dados coletados foram registrados em questionários, anotações, fotos, vídeos, em forma de tabelas ou planilhas, de acordo com a especificidade de cada informação.

Os equipamentos que foram utilizados nos treinamentos proprioceptivos são: disco de equilíbrio da marca Acte ${ }^{\circledR}$ de plástico com $39 \mathrm{~cm}$ de diâmetro, almofada de ar da marca Mercur ${ }^{\circledR} \operatorname{com} 30 \mathrm{~cm}$ de diâmetro, prancha de equilíbrio médio lateral de madeira de $28 \mathrm{~cm}$ de largura por $65 \mathrm{~cm}$ de comprimento, bola de basquete oficial da marca Wilson e colchonetes utilizados em academia (Figura 3.1). 


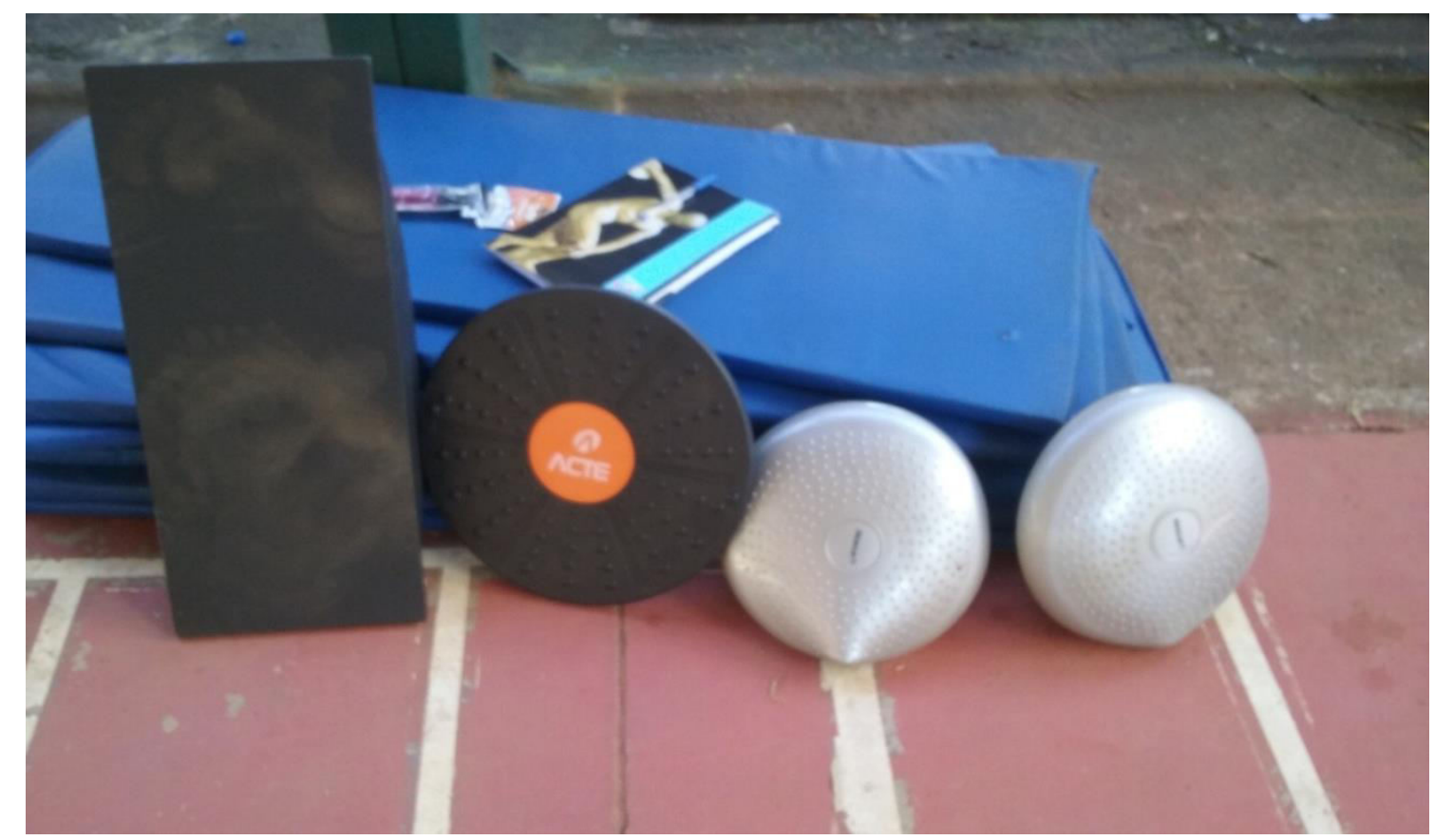

Figura 3.1: Equipamentos utilizados no treinamento proprioceptivo.

A massa corporal foi aferida pela balança (marca Filizola ${ }^{\circledR}$ eletrônica/digital; resolução de 100g; modelo Personal Line) e a estatura medida por meio do estadiômetro Country Tecnology ${ }^{\circledR}$ (modelo 67031; resolução de $1 \mathrm{~cm})$.

O percentual de gordura foi determinado usando o kit de avaliação da marca Cescorf Equipamentos ${ }^{\circledR}$ e com a planilha eletrônica que vem com o equipamento. Todos estes procedimentos foram realizados antes de iniciar a intervenção e ao final do programa de treinamento proprioceptivo para verificar se houve mudanças significativas nas características físicas na amostra.

Os participantes responderam o questionário adaptado, Ankle Joint Functional Assessment Tool - AJFAT (ANEXO C) sobre instabilidade de tornozelos e comparação funcional entre os tornozelos (ROSS et al., 2009), validado no Brasil por SUDA \& COELHO (2012).

Este questionário compara a sensitividade, a especificidade, e a probabilidade de identificar indivíduos com instabilidade na articulação do tornozelo. Cada item apresenta cinco opções de respostas (escala de Likert de zero a quatro). A ferramenta tem 12 perguntas: cinco relacionadas às limitações (dor, estabilidade, rigidez, força, falseio), quatro relacionadas às atividades (andar em superfícies irregulares, mudanças de direção durante a corrida, correr, descer escadas) e três itens de qualidade geral. 
A pontuação máxima é de 48 pontos, pontuações acima de 36 indicam muita instabilidade funcional no tornozelo, entre 20 e 35 pontos indicam pouca instabilidade funcional no tornozelo e por fim, pontuações abaixo de 20 pontos indicam nenhuma ou quase nenhuma instabilidade funcional no tornozelo.

Os voluntários também responderam o Questionário Internacional de Atividade Física - IPAQ (Versão Curta), para determinar o nível de atividade física fora dos treinos (ANEXO D).

Por fim os participantes responderam um Questionário de Caracterização adaptado de BONETTI et al. (2012), sobre a prática de atividade física fora dos treinos de basquetebol e informações sobre lesões, afastamento dos treinos e jogos e o uso de órteses em treinos e jogos. (ANEXO E). Todos estes questionários foram aplicados para os grupos $\mathrm{GC} e$ $\mathrm{GE}$, antes do início da coleta pré-intervenção.

\subsection{Aquisição dos Dados}

Foi utilizada uma Plataforma de Força Portátil modelo Accu Sway Plus da marca Advanced Mechanical Technologies, Inc (AMTI), instrumento que permite aferir o deslocamento do CP dos indivíduos (Figura 3.2), com uma taxa de aquisição de $100 \mathrm{~Hz}$.

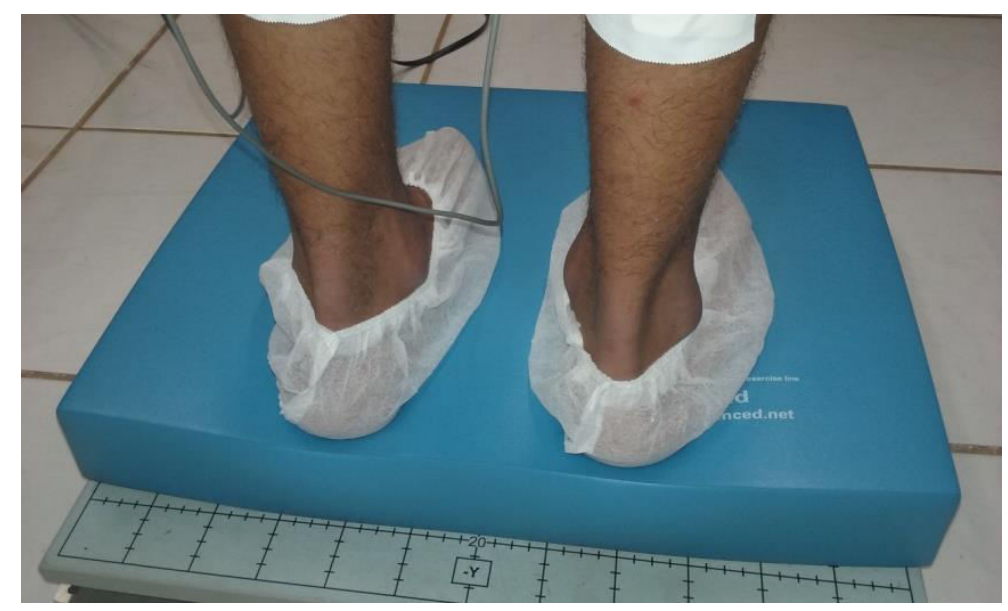

Figura 3.2: Espuma de Alta Densidade sobre a plataforma de força AMTI.

Nas coletas dos testes pré e pós-intervenção utilizou-se sobre a plataforma de força uma espuma de alta densidade da marca AIREX Professional Exercise Line, de dimensões 50x41×06 cm. 
Para a obtenção de dados da eletromiografia utilizou-se o eletromiógrafo da marca Delsys Bagnoli-2 EMG System (Figura 3.3), instrumento que permite coletar os dados de ativação muscular dos participantes.

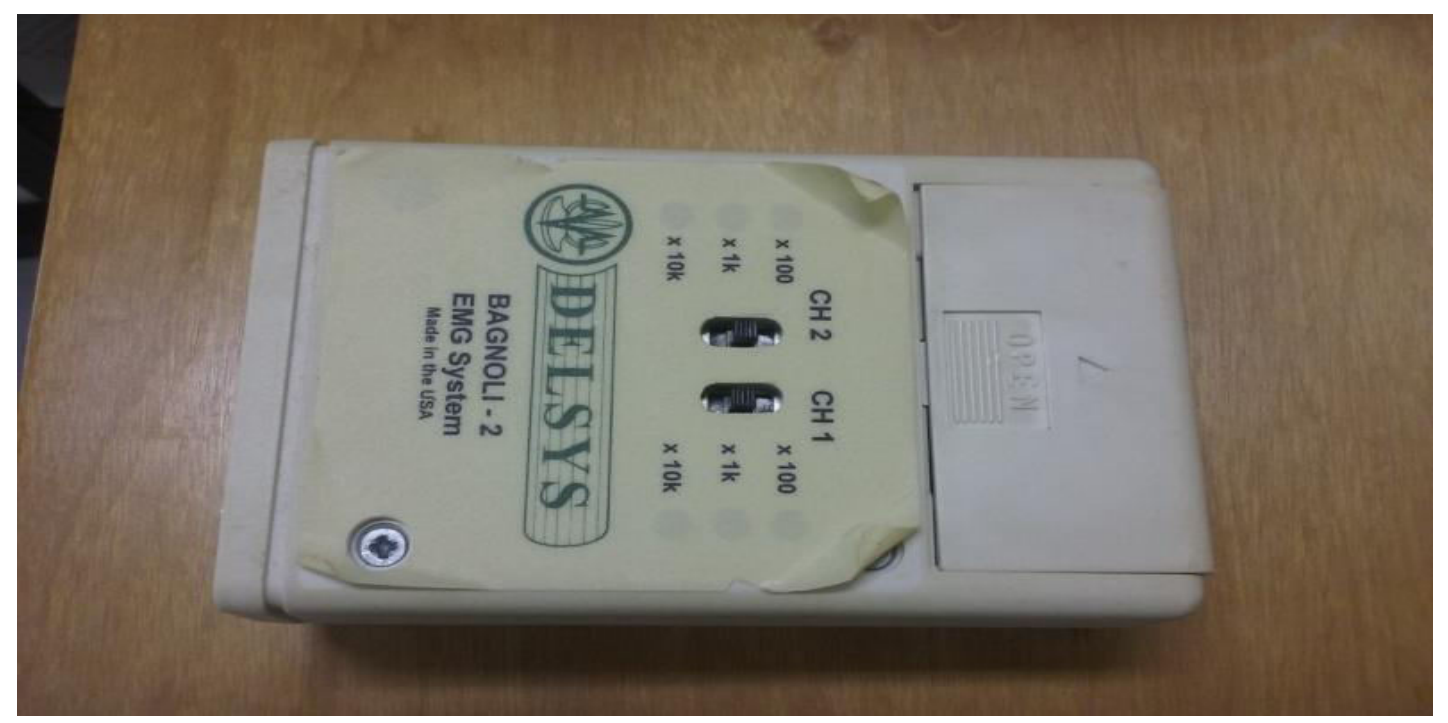

Figura 3.3: Eletromiógrafo Delsys.

A taxa de amostragem foi de $2 \mathrm{KHz}$, o ganho foi de 1.000x e a frequência de corte do filtro passa-baixas foi de $500 \mathrm{~Hz}$. Um sinal de referência foi utilizado para indicar o início da coleta na plataforma de força.

Cada eletrodo foi associado em um canal do sistema Lab View Versão 3.1 (Figura 3.4), que registrou o sinal eletromiográfico do músculo soleus de ambas as pernas e o sinal de referência.

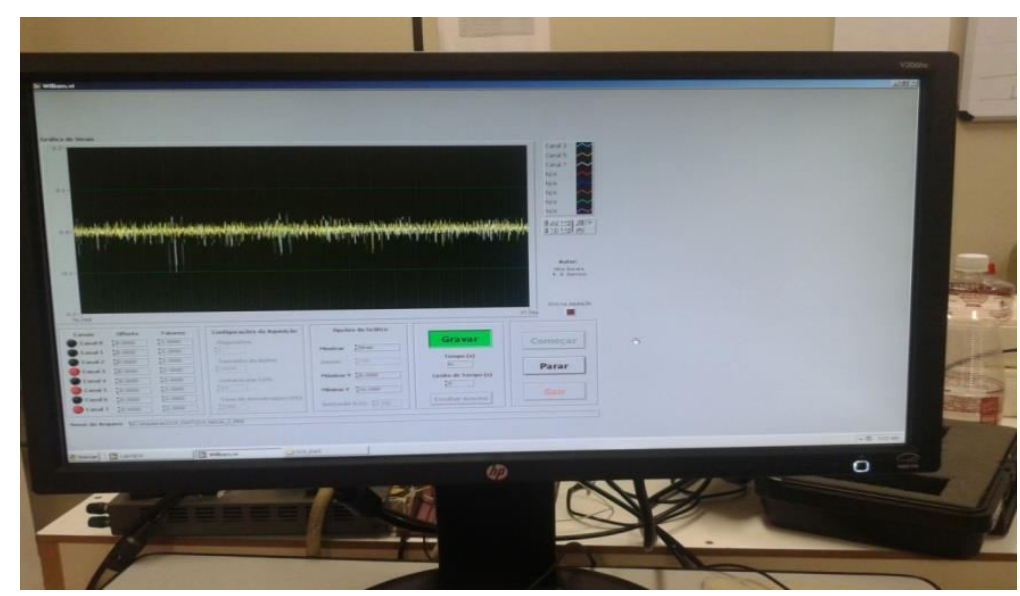

Figura 3.4: Aquisição do EMG com o Lab View 3.1. 
Eletrodos de superfície foram fixados nos voluntários por meio de esparadrapo anti-alérgico no músculo soleus de cada perna, após assepsia da pele com álcool $96 \%$. O eletrodo terra foi fixado no punho da mão esquerda (Figura 3.5).

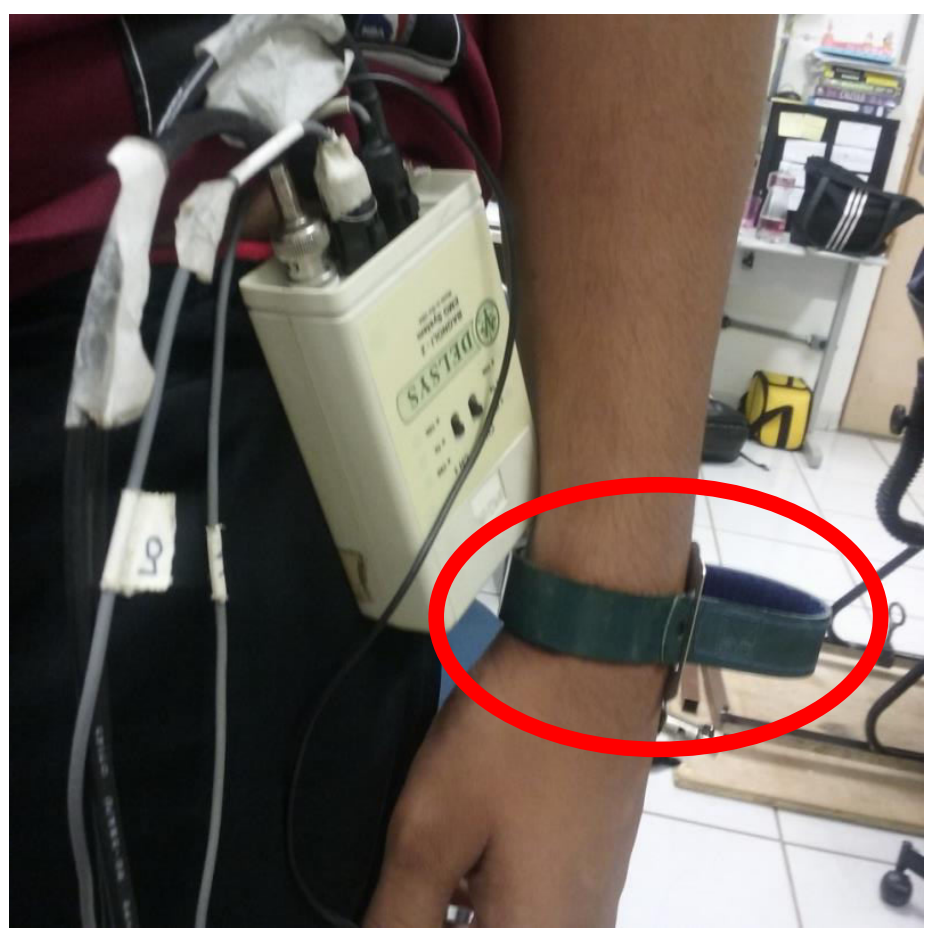

Figura 3.5: Posicionamento do eletrodo terra de captação.

\subsection{Processamento de Sinais}

O RMS em ambas as direções (ântero-posterior e médio-lateral) foi calculado. A área do estabilograma, ou seja, a área da elipse que encerra $85 \%$ dos valores do CP obtidos ao longo do tempo em ambas as direções, foi calculada pela análise das componentes principais (OLIVEIRA et al., 1986).

Para a VM foi obtida a diferença entre cada ponto do sinal do centro de pressão no sentido ântero-posterior (CP_ap) e no sentido médio-lateral (CP_ml), função diff do MATLAB, e em seguida calculada a média dos valores absolutos destas diferenças.

Esta média foi então dividida pelo intervalo de tempo entre cada ponto do sinal, ou pelo inverso da frequência de amostragem, equivalente ao cálculo sugerido na literatura (VUILLERME et al., 2001; MEZZARANE \& KOHN, 2008): 


$$
V M=(1 / T) \sum_{i=1}^{N} \frac{\left|\left(C P_{-} a p_{i}-C P_{-} a p_{i-1}\right)\right|}{N}
$$

em que $T$ é o inverso da frequência de amostragem do sinal e $N$ é o número de amostras. A média das três tentativas para cada sujeito foi calculada para as variáveis descritas acima.

A magnitude quadrática da coerência espectral do EMG do músculo soleus de ambas as pernas foi estimada. A transformada rápida de Fourier (Fast Fourier Transform - FFT) foi calculada para cada segmento do EMG, que foi dividido em 30 regiões sem superposição, e uma média foi obtida utilizando método de Welch com 4.000 amostras por periodograma, resultando em uma resolução espectral de 0,2 Hz. Uma janela Hanning foi especificada para cada segmento.

A densidade espectral de potência dos eletromiogramas retificados dos músculos soleus de ambas as pernas $\left(f_{x x}\right.$ e $\left.f_{y y}\right)$ e o espectro cruzado $\left(f_{x y}\right)$ foram obtidos. A função de coerência $\left(R_{x y}(\lambda)\right)$ foi estimada de acordo com a fórmula abaixo utilizando o software MATLAB (Mathworks v.2014):

$$
R_{x y}(\lambda)=\frac{f_{x y}(\lambda)}{\sqrt{f_{x x}(\lambda) f_{y y}(\lambda)}}
$$

em que $\lambda$ é a frequência.

Estes parâmetros foram avaliados em dois momentos distintos, pré e pós-intervenção de oito semanas de treinos proprioceptivos.

\subsection{Procedimentos}

Os voluntários permaneceram em pé, sobre uma espuma de alta densidade, que estava alocada na plataforma de força, com os pés paralelos na largura dos quadris e de olhos fechados.

Três tentativas foram realizadas para cada voluntário, o sujeito permaneceu sobre a plataforma por 70 segundos, tendo um descanso de pelo menos 60 segundos entre as tentativas (RUGELJ \& SEVSEK, 2007). Os 10 
primeiros segundos de cada coleta foram desconsiderados para que ocorresse a estabilização postural do voluntário.

\subsection{Coleta de Dados e Intervenção}

O projeto possui aprovação do Comitê de Ética e Pesquisa da Universidade de Brasília (CEP/FS-UnB), sobre o número de parecer 788.170 (ANEXO F). A coleta de dados seguiu a linha do tempo ilustrada na Figura 3.6 a seguir:

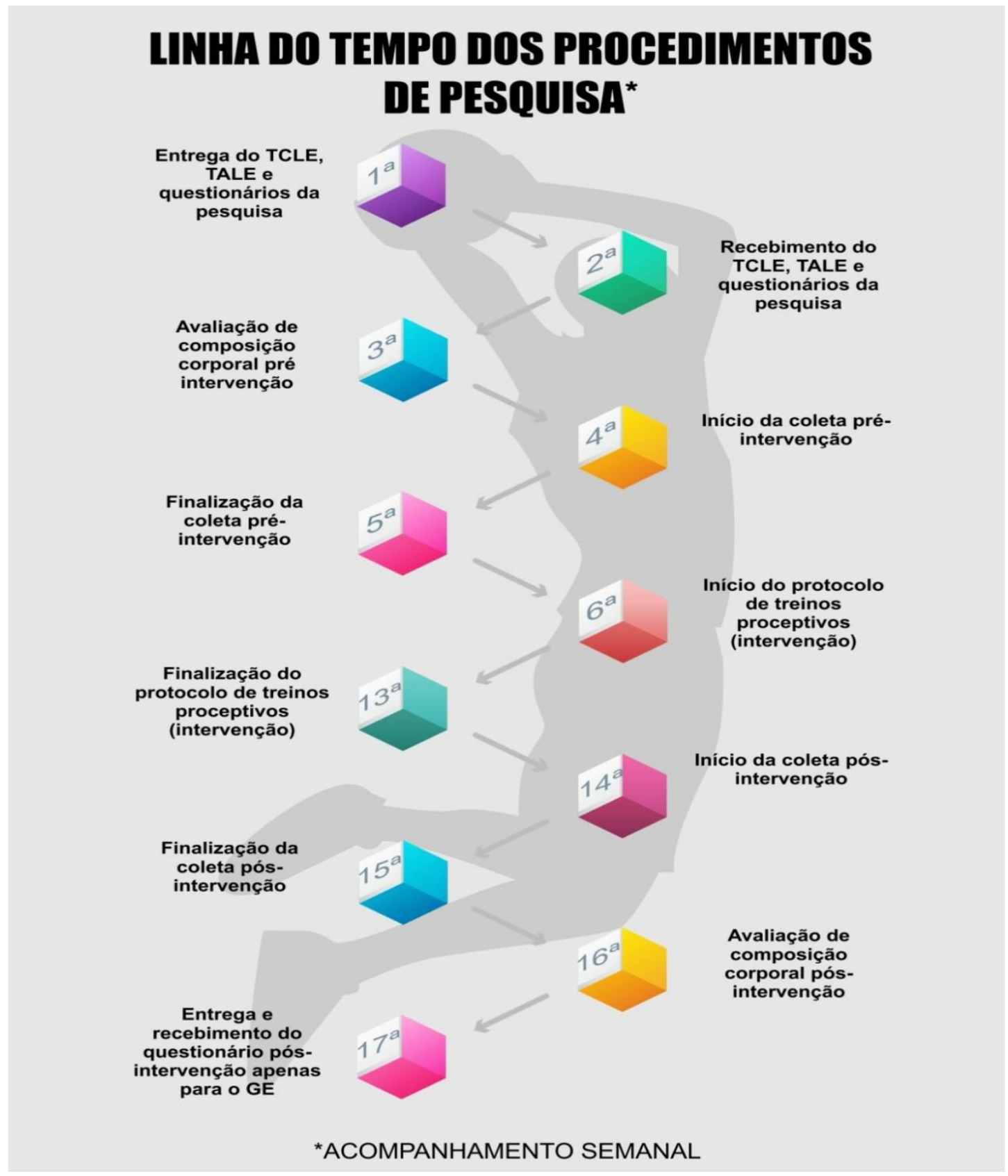

Figura 3.6: Linha do tempo representando o cronograma dos procedimentos de pesquisa. 


\subsection{Protocolo de Intervenção}

Para a realização da intervenção do presente estudo a amostra selecionada, após a análise dos critérios de inclusão e exclusão, foi dividida aleatoriamente em dois grupos, a aleatorização dos sujeitos foi realizada pelo programa de computador MATLAB (Mathworks v.2014, formando o GC com 15 sujeitos, que continuaram com os treinos de basquete normalmente e o GE composto por 15 sujeitos, que além do treino de basquetebol igual ao do GC fizeram treinos proprioceptivos orientados pelo pesquisador durante oito semanas com frequência de 3 sessões por semana.

O GE terminou o estudo com 14 voluntários, pois um dos sujeitos abandonou os treinos de basquetebol durante a pesquisa por motivos de saúde.

O procedimento consistiu em 3 sessões de treinos proprioceptivos por semana com duração entre 10 e 15 minutos, antes do treino de basquetebol e os exercícios foram divididos em quatro graus de dificuldade progressiva.

Os exercícios de grau um tinham como objetivo analisar se os sujeitos não omitiram alguma limitação articular, os exercícios eram sem elementos do basquetebol e consistia basicamente de colocar os voluntários para caminhar em superfícies diferentes apoiando diferentes partes dos pés.

Os exercícios de grau dois tinham elementos do basquetebol introduzidos, bola e posição básica de defesa, na sua execução, objetivando promover o primeiro contato do voluntário com o treino proprioceptivo e elementos do basquetebol.

Nos exercícios de grau três os elementos de basquetebol surgiram com mais volume nas tarefas, utilizando passes mais comuns existentes no jogo e o drible, todos os exercícios tinham como objetivo simular movimentos de jogo sobre superfícies instáveis.

Para finalizar os exercícios de grau quatro tinham tarefas que envolviam ações de jogo mais elaboradas, como cobrar o lance livre sobre uma superfície instável, com o olho aberto e depois com o olho fechado, além da realização do jump, que é um arremesso que o atleta perde o contato com a bola no ponto mais alto da fase aérea do movimento de arremesso, partindo-se de uma superfície instável, tendo como objetivo criar a situação mais desafiadora possível para os voluntários. 
Todos os exercícios utilizados no protocolo de intervenção foram adaptados de exercícios proprioceptivos sugeridos pelos autores: EILS \& ROSENBAUM (2001), CARAFFA et al. (1996), PLISKY et al. (2006), SHETH et al. (1997), VERHAGEN et al. (2004), PASANEN et al. (2008), adaptados à prática do basquetebol.

Os exercícios proprioceptivos estão divididos em quatro graus de dificuldades sendo progressivos descritos a seguir:

\section{Exercícios grau um (Figura 3.7):}

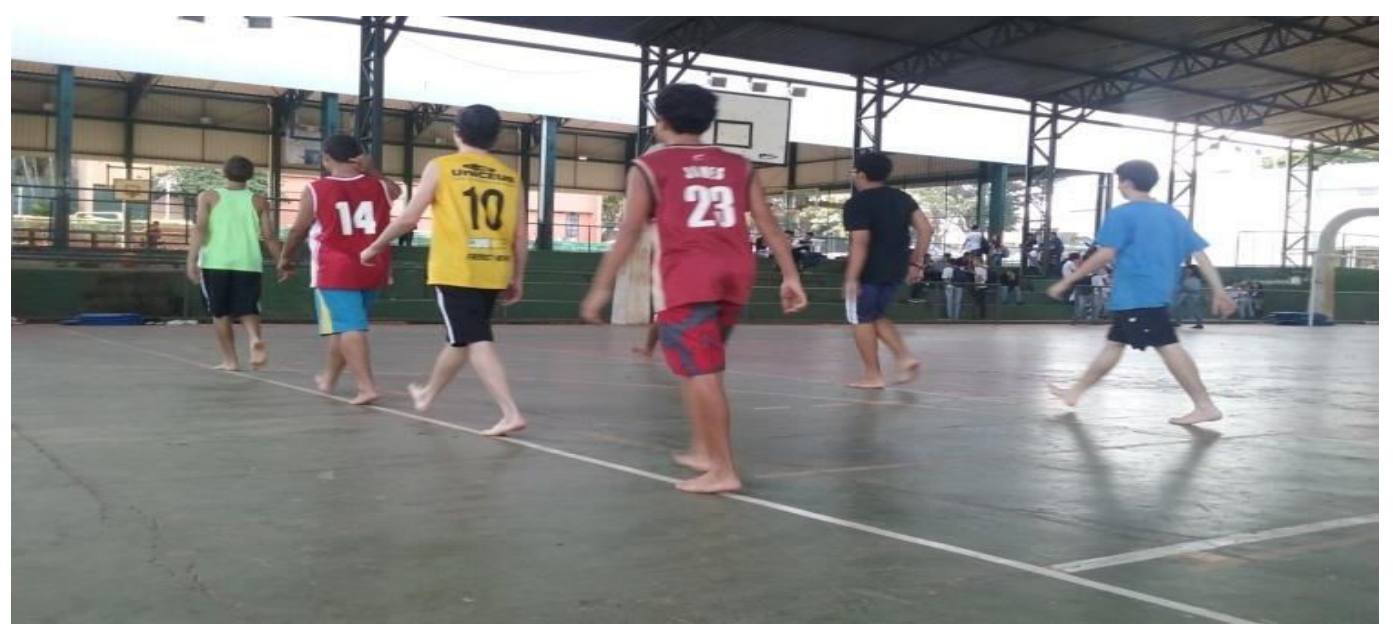

Figura 3.7: Exercício grau um.

- o voluntário caminhou por 2 vezes descalço sobre uma linha de 10 metros desenhada no chão podendo olhar para a linha;

- o voluntário caminhou por 2 vezes descalço sobre uma linha de 10 metros desenhada no chão com um pé a frente do outro (tocando calcanhar no dedão) podendo olhar para a linha;

- o voluntário caminhou por 2 vezes descalço sobre uma linha de 10 metros desenhada no chão sem poder olhar para a linha;

- o voluntário caminhou por 2 vezes descalço sobre uma linha de 10 metros desenhada no chão com um pé a frente do outro (tocando calcanhar no dedão) sem poder olhar para a linha;

- o voluntário caminhou descalço uma distância de 10 metros sobre diferentes planos intercalados ( 1 colchonete, piso, 2 colchonetes, piso, 3 colchonetes, piso e 2 colchonetes), utilizando os seguintes apoios: toda a 
planta do pé, calcanhar, ponta dos pés, bordas lateral e borda medial dos pés, por 2 vezes em cada situação, podendo olhar para linha.

- o voluntário caminhou descalço uma distância de 10 metros sobre diferentes planos intercalados (1 colchonete, piso, 2 colchonetes, piso, 3 colchonetes, piso e 2 colchonetes), utilizando os seguintes apoios: toda a planta do pé, calcanhar, ponta dos pés, bordas lateral e borda medial dos pés, por 2 vezes em cada situação, sem poder olhar para linha.

\section{Exercícios grau dois:}

- o voluntário, com o apoio unipodal sobre dois colchonetes e de costas para outro voluntário, passou a bola de basquetebol para trás, girando apenas o tronco, sustentando-se primeiro com a perna direita por 5 vezes e depois com a esquerda também por 5 vezes, alternando o sentido de entrega da bola;

- o voluntário executou um total de três agachamentos por série, sendo um total de 3 séries, driblando a bola de basquetebol com a mão dominante e o apoio de um pé só, primeiro com o membro dominante, depois com o membro não dominante, primeiro no chão, depois em cima de 1 colchonete e por fim em cima de 3 colchonetes. Com intervalo de 10 segundos entre as séries (Figura 3.8).

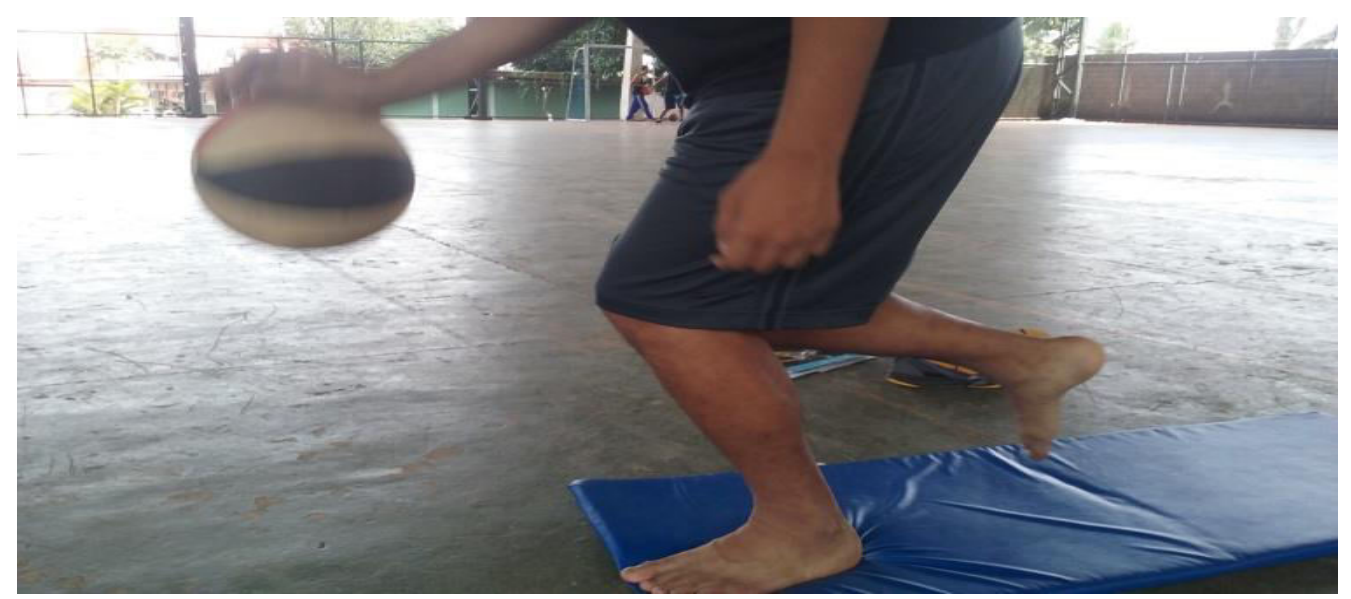

Figura 3.8: Exercício grau dois.

\section{Exercícios grau três:}

- o voluntário, em apoio bipodal e joelhos estendidos, buscaram manter o equilíbrio em 3 séries de pelo menos 10 segundos,primeiro na prancha de 
equilíbrio médio-lateral, depois no disco de equilíbrio, realizando passes de peito, com 10 segundos de descanso entre as séries;

- o voluntário realizou passes picados, por pelo menos 10 segundos, alternando a mão do passe, com o pé não dominante na prancha de equilíbrio médio-lateral e o pé dominante no disco de equilíbrio, realizando passes picados para as laterais de forma alternada, um passe para a esquerda e a outra vez para a direita, com 10 segundos de descanso entre as 3 séries;

- o voluntário executou 3 séries de 5 agachamentos com apoio bipodal com olhos abertos, depois outras 3 séries de 5 agachamentos com os olhos fechados nas almofadas de equilíbrio, com 10 segundos de descanso entre as séries;

- o voluntário executou 3 séries de 5 agachamentos driblando a bola com a mão dominante e com o apoio bipodal nas almofadas de equilíbrio, com 10 segundos de descanso entre as séries (Figura 3.9).

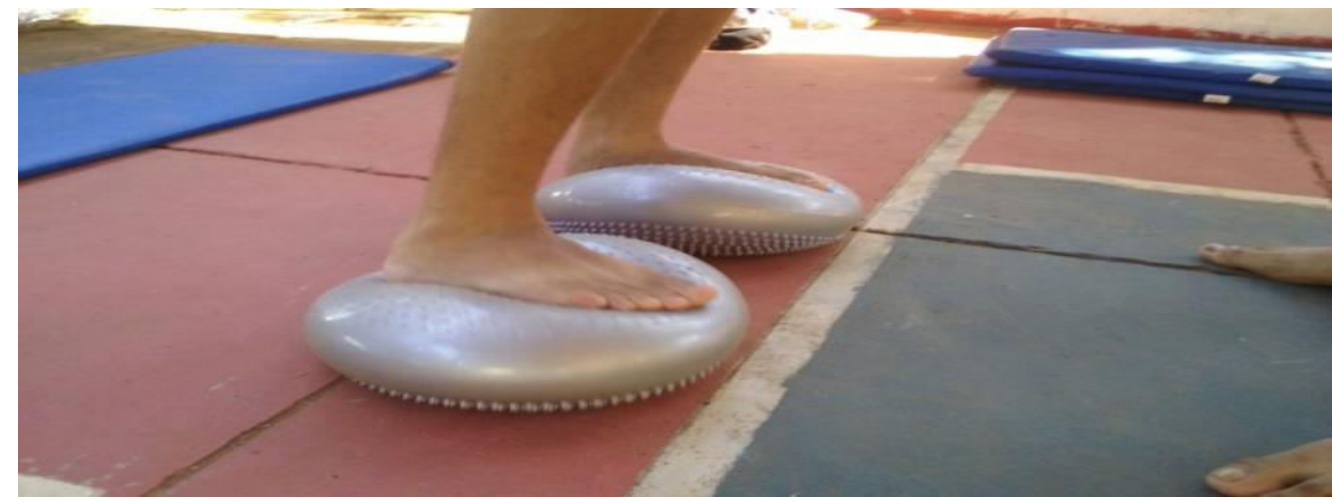

Figura 3.9: Exercício grau três.

\section{Exercícios grau quatro:}

- usando a prancha de equilíbrio médio lateral de forma bipodal, o voluntário, com os olhos fechados, tentou executar 5 lances livres;

- usando os discos de equilíbrio de forma bipodal, o voluntário, com os olhos fechados, tentou executar 5 lances livres;

- usando as almofadas de equilíbrio de forma bipodal, o voluntário, com os olhos fechados, tentou cobrar 5 lances livres;

- usando a prancha de equilíbrio médio lateral de forma bipodal, o voluntário, tentou arremessar por 3 vezes a bola na cesta, o equipamento 
estava em um raio entre $65-75 \mathrm{~cm}$ do aro e a bola num intervalo de $40-50^{\circ} \mathrm{da}$ tabela;

- usando os discos de equilíbrio de forma bipodal, o voluntário tentou arremessar por 3 vezes a bola na cesta, o equipamento estava em um raio entre $65-75 \mathrm{~cm}$ do aro e a bola num intervalo de $40-50^{\circ}$ da tabela;

- usando as almofadas de equilíbrio de forma bipodal, o voluntário tentou arremessar por 3 vezes a bola na cesta, o equipamento estava em um raio entre $65-75 \mathrm{~cm}$ do aro e a bola num intervalo de $40-50^{\circ}$ da tabela;

- o voluntário com apoio bipodal, na prancha de equilíbrio médio lateral, tentou por 3 vezes realizar o jump (aterrissando a frente do ponto de partida), o equipamento estava em um raio entre $65-75 \mathrm{~cm}$ do aro e a bola num intervalo de $40-50^{\circ}$ da tabela;

- o voluntário com apoio bipodal, nos discos de equilíbrio, tentou por 3 vezes realizar o jump (aterrissando a frente do ponto de partida), o equipamento estava em um raio entre $65-75 \mathrm{~cm}$ do aro e a bola num intervalo de $40-50^{\circ}$ da tabela;

- o voluntário com apoio bipodal, nas almofadas de equilíbrio, tentou por 3 vezes realizar o jump (aterrissando a frente do ponto de partida), o equipamento estava em um raio entre $65-75 \mathrm{~cm}$ do aro e a bola num intervalo de $40-50^{\circ}$ da tabela (Figura 3.10).
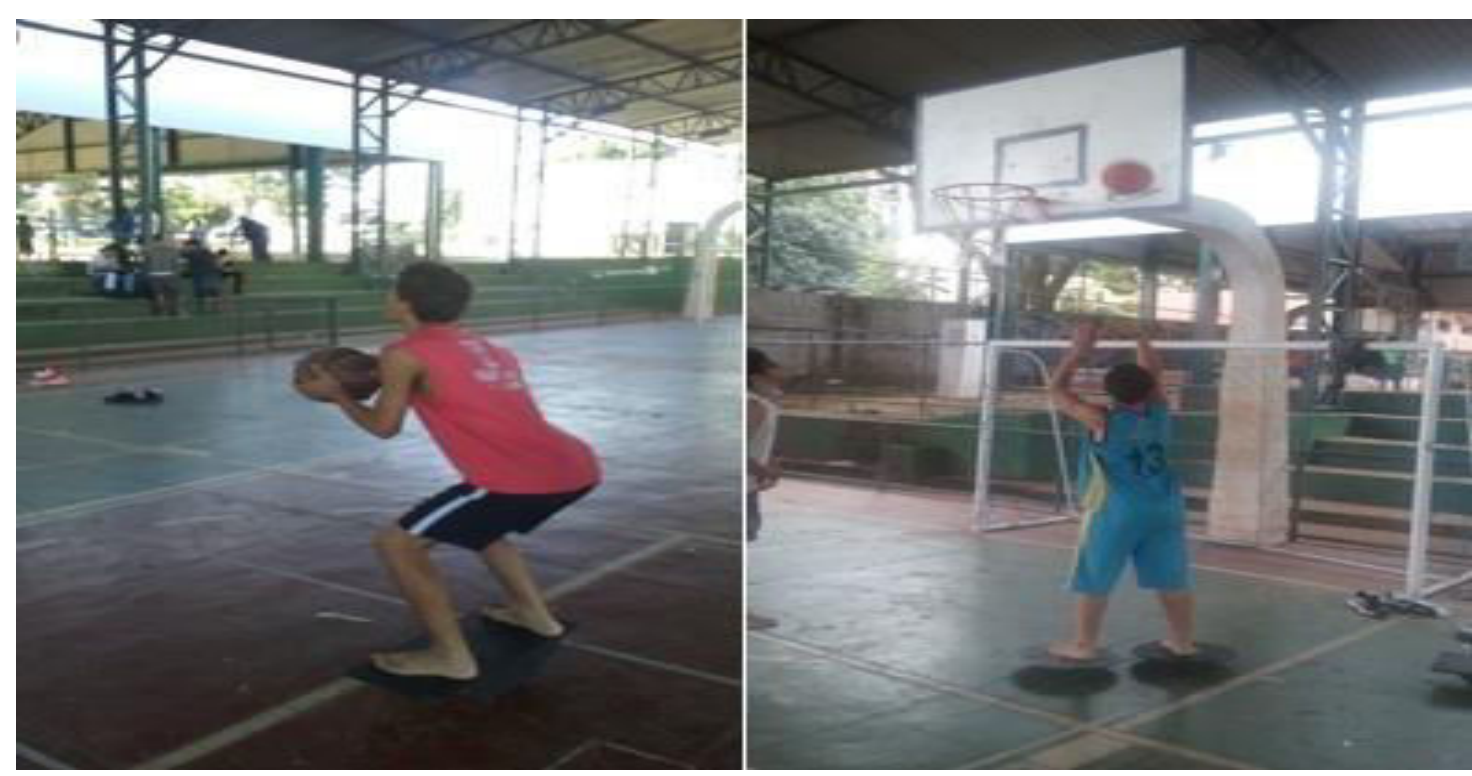

Figura 3.10: Exercício grau quatro. 


\subsection{Análise Estatística}

Para as variáveis de caracterização da amostra do estudo foi utilizado um cálculo de média e desvio padrão. Também foi realizado um teste ANOVA para verificar se existe algum modelo de regressão significante, e o teste de Wald para identificar em qual variável ocorreu a significância estatística, utilizando o processo de seleção de varáveis stepwise.

Este procedimento visa identificar se alguma variável de caracterização (idade, estatura, massa corporal, IMC, \%G, posição em quadra ou tempo de basquetebol) influenciava algum dos resultados das variáveis dependentes (RMS, VM, área da elipse e/ou coerência espectral).

A normalidade dos dados coletados durante a pesquisa foi verificada com a utilização do teste de Shapiro-Wilk e a homogeneidade pelo teste de Levene. Testada e confirmada a normalidade e a homogeneidade foi aplicado um teste ANOVA de duas vias (two way) para comparação entre as médias das variáveis intra grupos e um teste $\mathrm{t}$ student não pareado para identificar diferenças significativas entre as diferenças das médias entre os grupos, por fim foi executado um teste post hoc de Bonferroni para identificar onde ocorreram as diferenças significativas encontradas no teste ANOVA neste estudo.

Uma função de coerência conjunta $\left(\left|\hat{R}_{x y}(\lambda)\right|^{2}\right)$, entre os eletromiogramas do músculo soleus de ambas as pernas, será estimada para condensar a estrutura da correlação de todos os sujeitos em cada situação (antes e após o treinamento proprioceptivo) utilizando-se a equação:

$$
\left|\hat{R}_{x y}\right|^{2}=\left|\frac{\sum_{i=1}^{k} L_{i} R_{x y}^{i}(\lambda)}{\sum_{i}^{k} L_{i}}\right|^{2}
$$

em que $R_{x y}^{i}$ é a coerência individual, $L_{i}$ é o número de segmentos necessários para estimar a coerência individual, e $k$ é o número de sujeitos (OBATA et al., 2014). Para a comparação estatística nas diferentes condições (antes e após intervenção), os valores de coerência serão transformados (normalizados) para escore $z$ (ROSENBERG et al., 1998). Esses escores serão determinados para 
cada sujeito em frequências já investigadas na literatura (0-4 Hz e 8-12 Hz) (OBATA et al., 2014). Um teste ANOVA de duas vias (two way) foi utilizado para detectar possíveis diferenças nos escores $z$ nas situações antes e após 0 período de treinamento e um teste $\mathrm{t}$ student não pareado para identificar diferenças significativas entre as diferenças das médias entre os grupos. 0 nível de significância adotado foi de $p<0,05$ e foi utilizado o programa SPSS 19.0 para executar os testes estatísticos, foi executado também um post hoc de Bonferroni para identificar onde ocorreram as diferenças significativas encontradas no teste ANOVA para a coerência espectral. 


\section{RESULTADOS}

\subsection{Caracterização da Amostra}

A caracterização da amostra ocorreu por meio de cálculo de média e desvio padrão, as variáveis, idade em anos, estatura em metros, massa corporal total em quilos, índice de massa corporal (IMC) em $\mathrm{kg} / \mathrm{m}^{2}$, percentual de gordura (Protocolo de Slaughter) e tempo de prática do basquetebol em meses, os resultados para o momento pré-intervenção estão na Tabela $1 \mathrm{e}$ para o momento pós-intervenção houve nova caracterização para analisar com teste estatístico se houve alteração significativa nas características físicas dos participantes os momentos pré e pós-intervenção (Tabela 2).

Tabela 1: Caracterização do GE e do GC Pré-intervenção

\begin{tabular}{ccc}
\hline \multirow{2}{*}{ Variáveis } & \multicolumn{2}{c}{ Grupo } \\
& Experimental & Controle \\
\hline Idade (anos) & $14,3 \pm 0,8$ & $14,4 \pm 1,1$ \\
Estatura $(\mathrm{m})$ & $1,71 \pm 0,09$ & $1,73 \pm 0,09$ \\
Peso $(\mathrm{Kg})$ & $65,5 \pm 17,7$ & $61,2 \pm 8,8$ \\
IMC $\left(\mathrm{Kg} / \mathrm{m}^{2}\right)$ & $22,1 \pm 4,0$ & $20,3 \pm 1,9$ \\
$\% \mathrm{G}$ & $17,9 \pm 5,5$ & $18,0 \pm 6,0$ \\
Tbasq (meses) & $18,6 \pm 6,4$ & $23,4 \pm 9,7$ \\
\hline IMC = índice de massa corporal; \%G = percentual de gordura; \\
\multicolumn{2}{c}{ TBasq = tempo de prática de basquetebol }
\end{tabular}

Tabela 2: Caracterização do GE e do GC Pós-intervenção

\begin{tabular}{ccc}
\hline \multirow{2}{*}{ Variáveis } & \multicolumn{2}{c}{ Grupo } \\
& Experimental & Controle \\
\hline Idade (anos) & $14,6 \pm 0,7$ & $14,5 \pm 1,0$ \\
Estatura $(\mathrm{m})$ & $1,71 \pm 0,10$ & $1,74 \pm 0,09$ \\
Peso $(\mathrm{Kg})$ & $64,4 \pm 16,3$ & $61,5 \pm 8,0$ \\
IMC $\left(\mathrm{Kg} / \mathrm{m}^{2}\right)$ & $21,7 \pm 3,4$ & $20,3 \pm 1,8$ \\
$\% G$ & $16,5 \pm 4,2$ & $17,0 \pm 4,4$ \\
Tbasq (meses) & $20,6 \pm 6,4$ & $25,4 \pm 9,7$
\end{tabular}

$\overline{\mathrm{IMC}}=$ índice de massa corporal; $\% \mathrm{G}=$ percentual de gordura;

TBasq $=$ tempo de prática de basquetebol 
Foi realizada uma análise estatística com o teste t-student não pareado (ou independente) para verificar se ocorreram diferenças significativas nas variáveis de caracterização (idade, estatura, Peso, IMC, \%G e Tempo de Basquete) da amostra entre os grupos nos momentos pré e pós-intervenção.

Não foram constatadas diferenças significativas comparando os resultados entre os grupos nos momentos pré e pós-intervenção.

Os resultados obtidos pelo AJFAT para os voluntários foram todos com pontuações menores que 20 pontos, indicando assim, de acordo com o AJFAT, que nenhum deles apresentou algum tipo de instabilidade funcional na articulação do tornozelo em nenhum dos membros inferiores.

Todos os voluntários foram classificados, segundo o IPAQ (Versão Curta), em Muito Ativos, 18 voluntários, ou Ativos, 11 voluntários, não havendo muita diferença nas respostas, o que determinou a classificação diferente foi o meio de transporte usado pelos voluntários para se locomover no dia a dia e a distância entre residência e escola.

Os voluntários responderam o questionário com respostas semelhantes, a única que merece destaque foi de um dos participantes que se locomove de skate a 8 anos, usa como meio de transporte para escola, curso e lazer, no mais todos tem uma rotina muito parecida de atividade física durante a semana e características parecidas sobre lesões e prática do basquetebol.

Todos os resultados das variáveis pesquisadas neste estudo (RMS, Vm, área da elipse e coerência espectral) são representados nas figuras por média e erro padrão da média e houve normalidade dos dados e a esfericidade foi aceita.

A Figura 4.1 mostra o deslocamento do CP_ap de um sujeito representativo e a correspondente atividade eletromiográfica do músculo soleus da perna direita.

Pode-se notar, por análise qualitativa, o alto grau de correlação entre ambos os sinais, ou seja, enquanto a atividade do soleus é maior observa-se um deslocamento do CP para o sentido anterior (valores positivos da ordenada do painel superior) e vice-versa. 

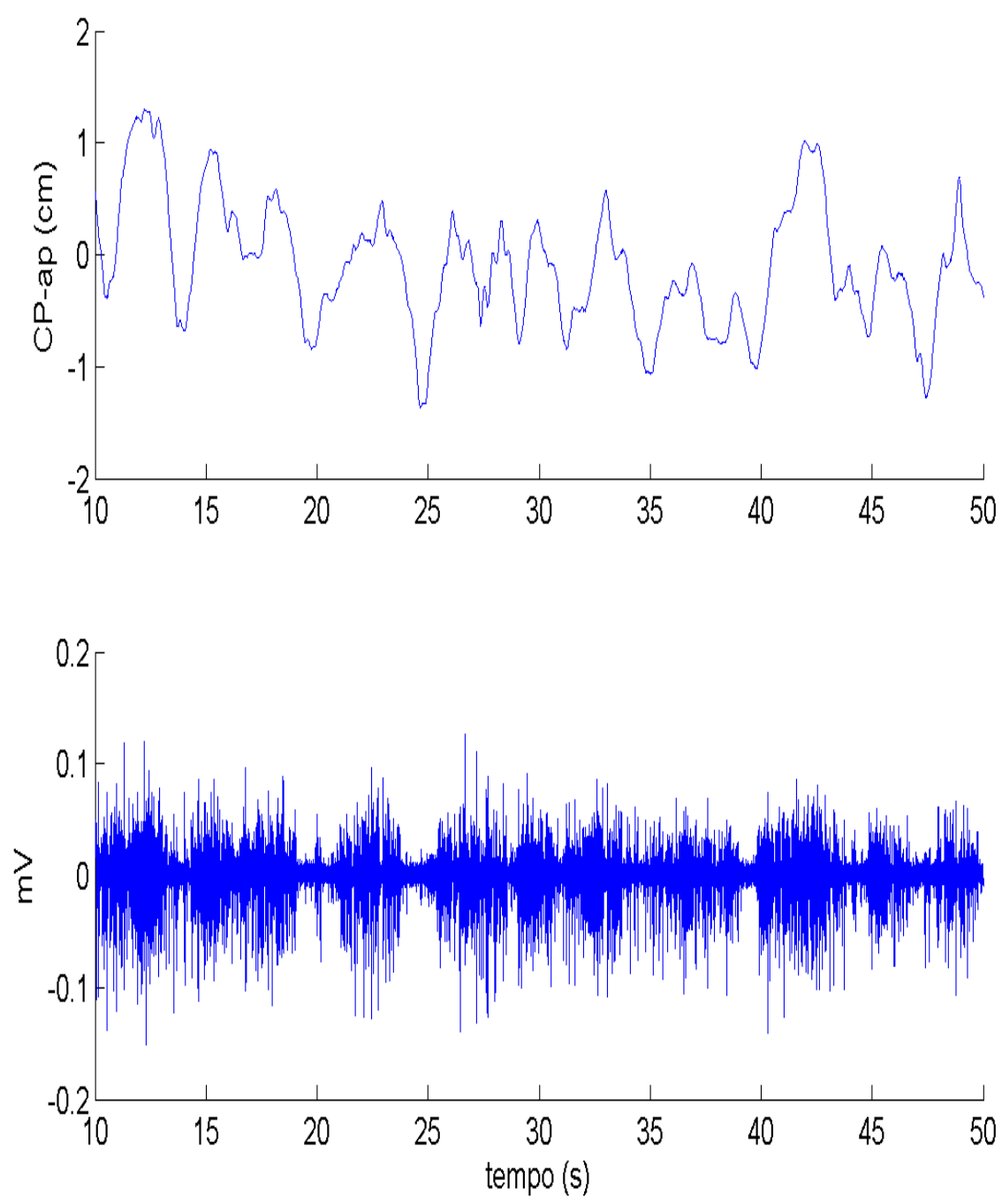

Figura 4.1: Sinais de um sujeito representativo mostrando no painel superior o CP_ap e no painel inferior a atividade eletromiográfica do soleus da perna direita.

\subsection{RMS do CP na Direção médio-lateral}

Na Figura 4.2 encontram-se os valores obtidos para a variável RMS na direção médio-lateral para o GC e GE nos momentos pré e pós-intervenção.

Pode-se observar que não houve nenhuma diferença significativa entre os momentos pré e pós-intervenção para nenhum dos grupos, indicando que o treino tático, técnico e físico do basquetebol com ou sem utilização de um programa de exercícios proprioceptivos durante oito semanas para escolares adolescentes praticantes de basquetebol não tem influência para alterar de forma significativa os valores da variável. 


\section{Direção médio-lateral}

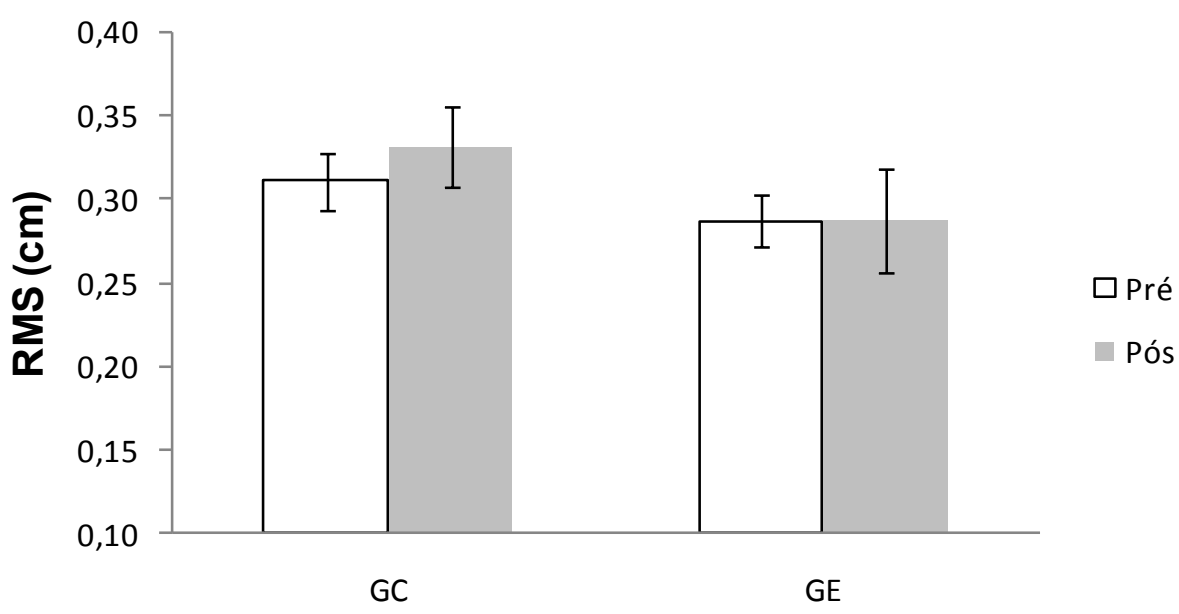

Figura 4.2: Média dos valores da variável RMS $(\mathrm{em} \mathrm{cm})$ do $\mathrm{CP} \_\mathrm{ml}$ medido antes e após o período de treinamento do GC e GE.

\subsection{RMS do CP na Direção ântero-posterior}

A Figura 4.3 mostra os resultados obtidos para a variável RMS na direção ântero-posterior do GC e do GE nos momentos pré e pós-intervenção.

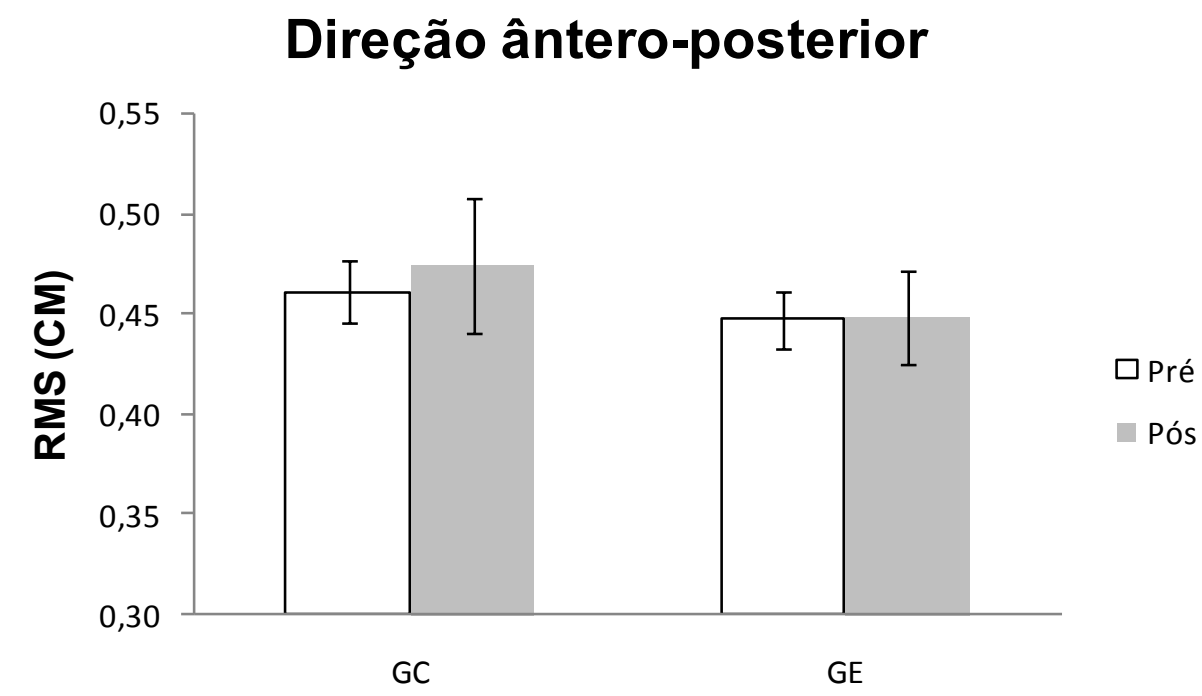

Figura 4.3: Média dos valores da variável RMS $(\mathrm{em} \mathrm{cm})$ do $\mathrm{CP}$ _ap medido antes e após o período de treinamento do GC e GE.

Observa-se que o $\quad$ GC e o $\quad$ GE não apresentaram diferenças estatisticamente significativas entre os momentos de coleta do estudo, pré e pós-intervenção, sugerindo que somente o treino tático, técnico e físico do 
basquetebol não tem influência estatisticamente significativa para a diminuição do valor médio da variável, o que também não ocorreu no grupo que foi aplicada a intervenção.

\subsection{Velocidade Média do CP na Direção médio-lateral}

A Figura 4.4 apresenta os resultados para a variável VM na direção médio-lateral do GC e do GE nos momentos pré e pós-intervenção

\section{Direção médio-lateral}

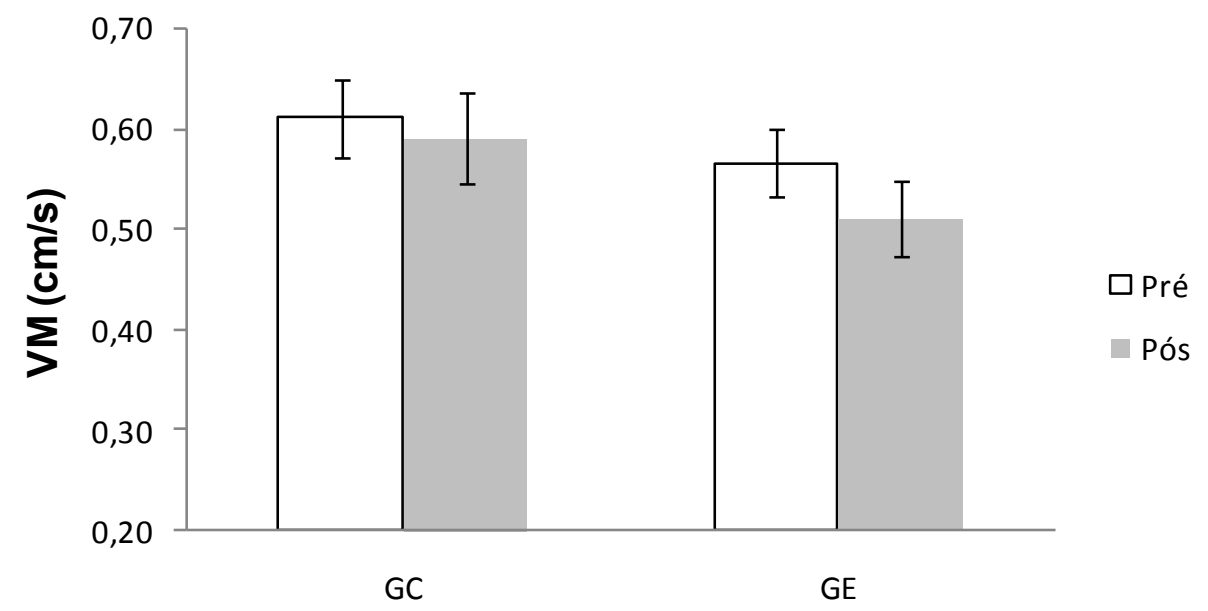

Figura 4.4: Média dos valores da variável VM $(\mathrm{em} \mathrm{cm} / \mathrm{s})$ do CP_ml medido antes e após o período de treinamento do GC e GE.

Observa-se que GC e o GE não apresentaram diferenças significativas no valor médio da variável, indicando que o treino tático, técnico e físico do time de basquetebol não influenciou na alteração do valor médio da variável, mesmo com a intervenção dos exercícios proprioceptivos não foi apontada nenhuma diferença entre os momentos da pesquisa.

\subsection{Velocidade Média do CP na Direção ântero-posterior}

Encontra-se na Figura 4.5 os resultados obtidos da variável VM na direção ântero-posterior para o GC e GE.

Observa-se que não houve diferenças significativas para o GC entre os momentos pré e pós-intervenção, apontando a ineficiência dos treinos táticos, técnicos e físicos do basquetebol para alterar o valor da variável entre os momentos da coleta. 


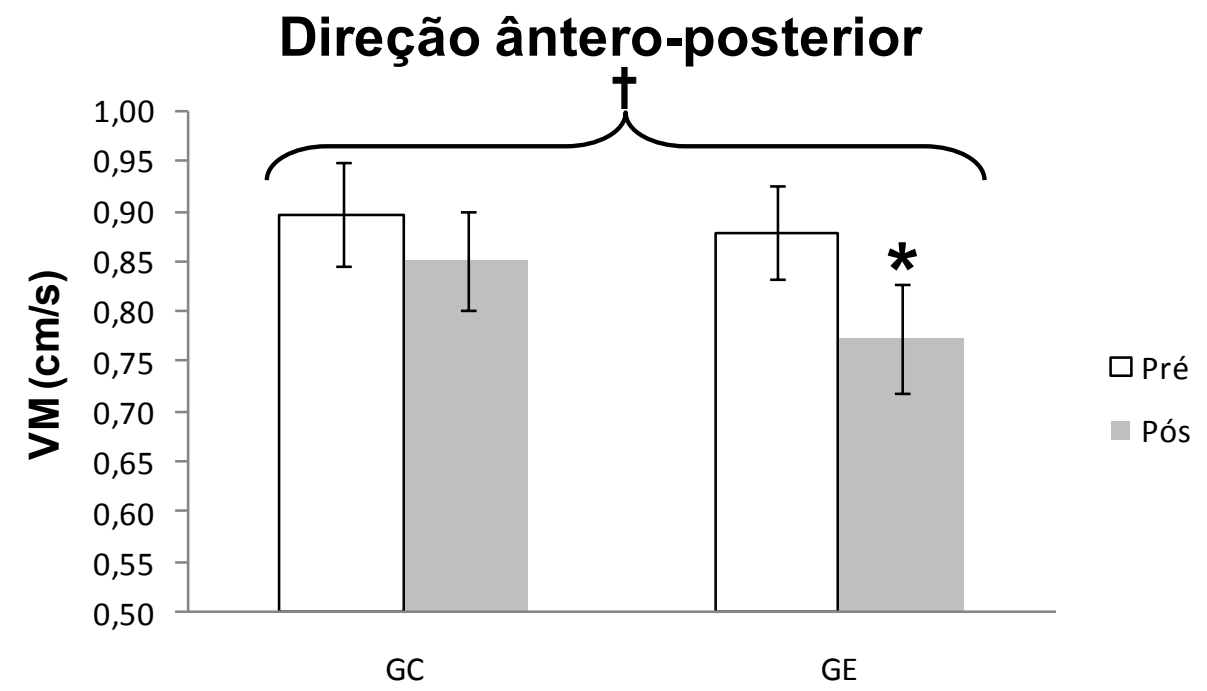

Figura 4.5: Média dos valores da variável VM $(\mathrm{em} \mathrm{cm} / \mathrm{s})$ do CP_ap medido antes e após o período de treinamento do GC e GE. ( ${ }^{*} p<0,05$ entre os momentos para o GE, $\uparrow p<0,05$ entre os grupos para a diferença das médias).

Para o GE houve diminuição significativa $\left({ }^{*} p<0,05\right)$, entre os momentos pré e pós-intervenção, no valor médio da variável indicando que o programa de treinos proprioceptivos aplicados ao GE durante as oito semanas conseguiu produzir uma diminuição estatisticamente significativa para a amostra que participou deste estudo.

Houve também uma diferença estatisticamente significativa $(\dagger p<0,05)$, quando comparado os resultados entre os grupos, ou seja, a diferença entre as médias obtidas pelos grupos, a diminuição da variável obtida pelo GC é estatisticamente significativa, se comparada com a diferença obtida pelo GE entre os momentos da pesquisa.

\section{6 Área da Elipse}

Na Figura 4.6 encontram-se os resultados obtidos para a variável área da elipse do GC e do GE, nos momentos pré e pós-intervenção, não foi encontrada nenhuma diferença significativa entre os momentos de coleta da pesquisa para nenhum dos grupos participantes deste estudo, indicando que os treinos de basquetebol não têm influência para uma diminuição do valor médio da variável, e que oito semanas de treinos proprioceptivos em escolares adolescentes praticantes de basquetebol também não tem efeito para alterar de forma significativa os valores da variável. 


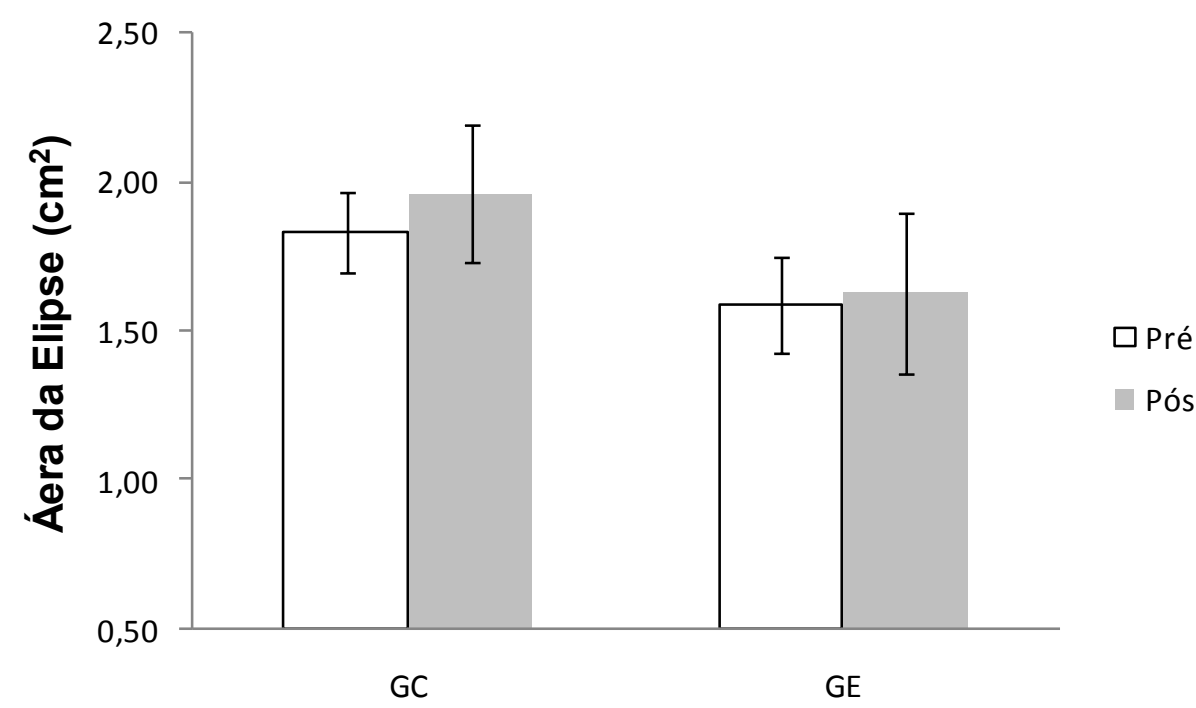

Figura 4.6: Média dos valores da variável área da elipse do CP medido antes e após o período de treinamento do GC e GE.

\subsection{Coerência Espectral 0-4 Hz}

A Figura 4.7 apresenta os resultados obtidos pelo GC e pelo GE para o z-score da coerência espectral no intervalo de frequência entre 0 e $4 \mathrm{~Hz}$ nos momentos pré e pós-intervenção.

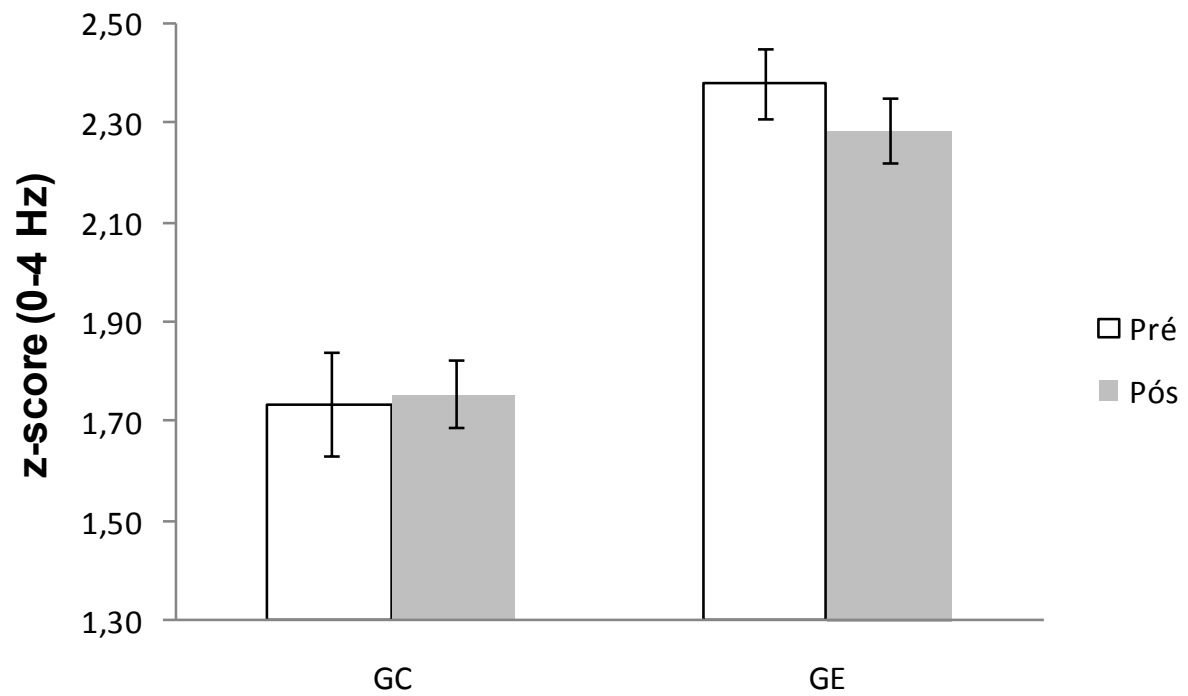

Figura 4.7: Média dos valores da variável coerência espectral frequência $0-4 \mathrm{~Hz}$ medido antes e após o período de treinamento do GC e GE.

Percebe-se que o GC não obteve valores com diferença estatisticamente significativa, indicando que para esta variável o treino de basquetebol não tem 
influência em uma possível alteração estatisticamente significativa entre os momentos de coleta, o mesmo ocorreu com o GE, sugerindo que a intervenção com os exercícios proprioceptivos não promovem influência em alterações dos valores desta variável.

\subsection{Coerência Espectral 8-12 Hz}

$\mathrm{Na}$ Figura 4.8 encontra-se os resultados obtidos para o z-score da coerência espectral na faixa de frequência entre 8 e $12 \mathrm{~Hz}$ para o GC e GE nos momentos pré e pós-intervenção.

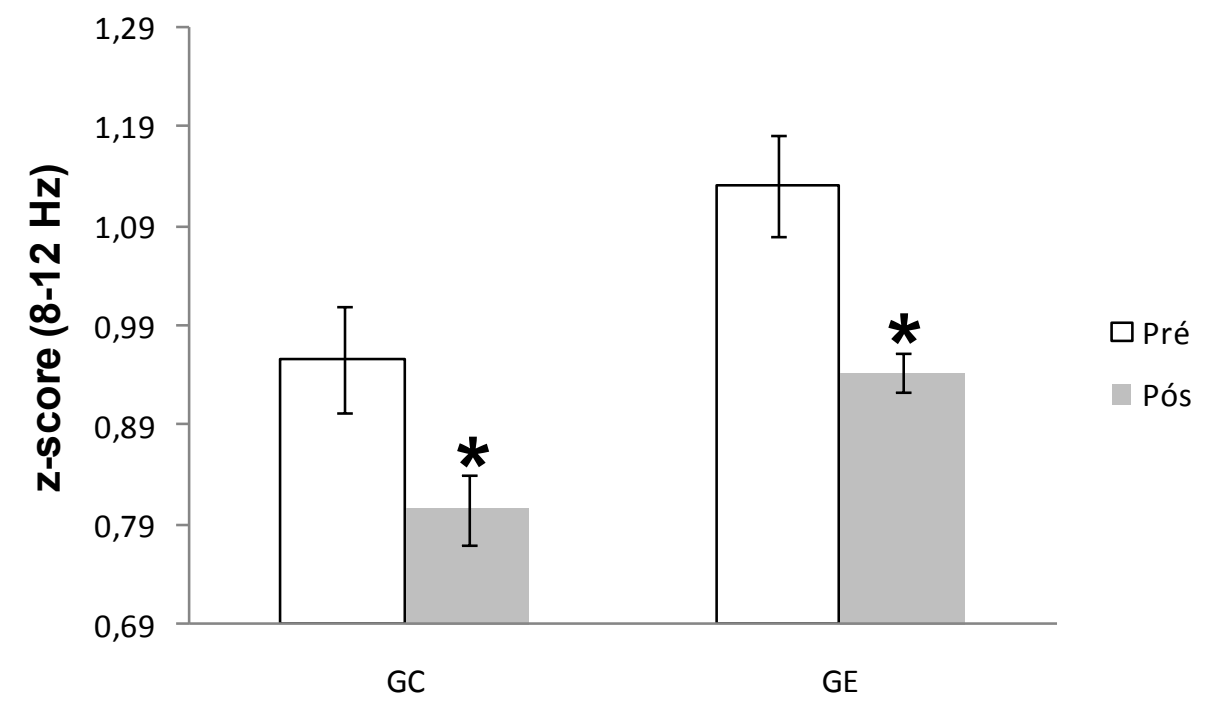

Figura 4.8: Média dos valores da variável coerência espectral na faixa de frequência 8-12 $\mathrm{Hz}$ medido antes e após o período de treinamento do GC e GE ( ${ }^{*} \mathrm{p}<0,05$ entre os momentos para o GE e para o GC).

Para ambos os grupos ocorreram diminuição significativa, $\left({ }^{*} p<0,05\right)$, indicando que o próprio treino físico, tático e técnico, aplicado no basquetebol pode influenciar na diminuição do valor da variável coerência espectral para a amostra que participou deste estudo entre os momentos pré e pós-intervenção. 


\section{DISCUSSÃO}

\subsection{Controle Postural}

Tem-se sugerido que o sistema de controle postural apresenta duas componentes, uma que opera a curtos intervalos de tempo e outra que opera a longos intervalos. (MEZZARANE \& KOHN, 2007). Essas componentes podem ser estudadas separadamente por meio de análise espectral. Contudo, um dos parâmetros medidos no domínio do tempo pode indicar as oscilações mais rápidas no deslocamento. $\mathrm{A} \mathrm{VM}$, que é calculada como sendo a soma das distâncias dividida pelo inverso da frequência, representa as oscilações mais rápidas do $\mathrm{CP}$ em comparação ao RMS. Estas oscilações rápidas podem estar associadas a um controle postural de curto prazo que estaria intimamente relacionado à atividade muscular (por exemplo, dos extensores do tornozelo) (MEZZARANE \& KOHN, 2007).

A VM tem sido interpretada como um indicador de estabilidade postural (WAJDA, 2015). Portanto, a diminuição nos valores de VM, como ocorreu no presente estudo, indica uma maior estabilização da postura nos indivíduos submetidos aos treinos proprioceptivos.

Melhoras na eficiência de manutenção do equilíbrio pode ser facilmente observada após um regime de treinamento proprioceptivo, que consiste em uma série de exercícios nos quais são apresentadas condições que desafiam o equilíbrio de maneira progressiva (PARKKARI et al., 2011). Esta melhora tem sido evidenciada, por exemplo, pela diminuição na oscilação postural, no caso do presente estudo os sujeitos que foram submetidos a treinos proprioceptivos demonstraram melhora no controle postural após intervenções com exercícios proprioceptivos. Os efeitos de programas de treinamento proprioceptivo (com duração variando de 4 a 8 semanas) sobre o controle postural têm sido reportados (ROZZl et al., 1999).

Por exemplo, atletas jovens do sexo masculino apresentaram uma diminuição significativa da VM na direção ântero-posterior depois de 8 semanas de treinos proprioceptivos, indicando uma melhora no controle postural (ZOUITA et al., 2013). No presente estudo o mesmo comportamento ocorreu, somando-se a observação de diminuição significativa da coerência espectral na faixa de frequência de $8-12 \mathrm{~Hz}$, então, sugere-se que o treinamento proprioceptivo tem influência nas componentes rápidas do controle 
postural. Estes resultados apontam para uma adaptação no controle postural, proporcionando uma melhor estabilização da postura na posição ereta.

CUMPS et al. (2007) sugeriram exercícios proprioceptivos na rotina de treinos de seis equipes de basquetebol com duração de 22 semanas, e com uma frequência de exercícios de 3 sessões por semana. Foram ministrados exercícios proprioceptivos antes do treino de basquetebol para um grupo de voluntários e no outro grupo apenas os treinos rotineiros de basquetebol. $O$ grupo que sofreu a intervenção apresentou diminuição significativa nos valores de VM na direção ântero-posterior. Os treinos proprioceptivos podem gerar uma antecipação nas contrações musculares em resposta às instabilidades na postura (no caso do presente estudo a falta das informações visuais e a superfície instável) para fornecer a proteção eficaz ao tornozelo (OSBOURNE et al., 2008).

Diferenças significativas na variável VM na direção ântero-posterior e na direção médio-lateral após 12 semanas de intervenção com treinos proprioceptivos foram observadas em pacientes com reconstrução de Ligamento Cruzado Anterior (LCA) (LEE et al., 2013). Para grupos que passaram por cirurgia nas articulações de MMII, 6 semanas de treinamento proprioceptivo já foram suficientes para apontar mudanças significativas (GRATHWOHL et al., 2006).

CLEYS et al. (2015), EMERY \& MEEUWISSE (2010) e FAIZULLIN \& FAIZULLINA (2015) não observaram diferença significativa nos valores de VM calculada para ambas as direções (médio-lateral e ântero-posterior) em atletas após quatro ou seis semanas de treinos com exercícios proprioceptivos. Este resultado mostra que, possivelmente, oito semanas de intervenção (como utilizado no presente estudo) seria a duração mínima para que as adaptações posturais pudessem se manifestar.

Houve uma diminuição significativa na VM na direção médio-lateral após regime de treinos proprioceptivos com duração de 6 semanas em um grupo pós-cirúrgico de LCA (BEYNNON et al., 2014). Neste caso a diminuição significativa ocorreu porque a amostra era composta por indivíduos que tinham limitações funcionais na articulação.

O treinamento proprioceptivo administrado juntamente aos treinos de basquetebol por oito semanas em escolares adolescentes não influenciam 
mudanças significativas na VM para a direção médio-lateral devido, provavelmente, as suas medidas já serem em grupos de pessoas treinadas (HOLM et al., 2004).

Atletas sem histórico de lesões no tornozelo nos últimos 18 meses não apresentaram diferença significativa no RMS em nenhuma das direções após treinos proprioceptivos. Tem sido postulado que o RMS não é muito sensível para detectar alterações posturais após treinos proprioceptivos, em indivíduos sem lesão nas articulações do tornozelo (VERHAGEN et al., 2004). No presente estudo a intervenção não induziu diferenças significativas no RMS em nenhuma das direções, sugerindo que para a componente lenta do controle postural, oito semanas de treinos proprioceptivos não são suficientes para promover mudanças estatisticamente significativas.

Não obstante, treinos proprioceptivos em atletas de futebol, que tiveram torção por inversão no tornozelo e após cirurgia de reconstrução de ligamento, geraram resultados significativos na diminuição dos valores de RMS na direção médio-lateral e também na direção ântero-posterior (ENGEBRETSEN et al., 2009). O mesmo procedimento de treinos foi aplicado em jovens atletas de basquetebol (CUMPS et al., 2007) e futebol (PASANEN et al., 2008) que não tinham nenhuma limitação funcional na articulação do tornozelo ou mesmo sofrido algum tipo de lesão nas articulações dos MMII. Nenhuma diferença significativa foi encontrada para os valores RMS. Desta forma, sugere-se que os treinos proprioceptivos promovem diminuição significativa nos valores do RMS e da VM nas direções médio-lateral e ântero-posterior em situações pósintervenções cirúrgicas, e/ou lesões na articulação do tornozelo, que induzem desestabilização no controle postural.

Os resultados obtidos no presente estudo e no desenvolvido por MCCRISKIN et al. (2015) são explicados pelo fato de pessoas que estão com limitações funcionais na articulação do tornozelo, devido à lesão ou cirurgia, apresentam valores mais altos de RMS nas duas direções, em comparação às pessoas que não estão com limitações na articulação do tornozelo. Portanto as mudanças apresentadas após intervenção com treinos proprioceptivos são mais evidentes.

A variável área da elipse no presente estudo não apresentou diferença significativa entre os momentos pré e pós-intervenção. Como a variável RMS 
para o GC e para o GE nas direções médio-lateral e ântero-posterior não mostraram diferenças significativas entre os momentos pré e pós-intervenção, espera-se que a área da elipse também não demonstre diferença significativa.

No estudo desenvolvido por AVELAR et al. (2016) com idosas que se submeteram ao treinamento de equilíbrio durante doze semanas foram obtidos resultados significativos para a variável área da elipse, enquanto que o grupo controle não apresentou diferenças significativas. No presente estudo a amostra é composta por adolescentes que não apresentam problemas funcionais nas articulações dos membros inferiores, o que pode explicar o não surgimento de diferenças significativas na área da elipse com apenas oito semanas de treinamento proprioceptivo.

\subsection{Ativação Muscular}

Na posição ereta quieta a articulação do tornozelo é fator primário na regulação da posição do corpo e do controle postural. O controle da postura é uma tarefa que requer ativações bilaterais dos músculos posturais, como os extensores de tornozelo (OBATA et al., 2014).

A organização bilateral de músculos responsáveis pela manutenção da posição ereta quieta tem sido foco crescente de vários estudos que utilizaram parâmetros espectrais obtidos de sinais eletromiográficos. Observou-se que a correlação entre a ativação de músculos extensores de ambas as pernas é mais acentuada em tarefas posturais em comparação a uma tarefa de isometria voluntária, por exemplo (GIBBS et al., 1995; MOCHIZUKI et al., 2006; MOCHIZUKI et al., 2007).

A manutenção da posição ereta quieta em condições que desafiam o equilíbrio, como na ausência da visão e sobre superfícies instáveis demandam adaptações no sistema de controle postural. Desta forma, as estratégias de controle postural decorrentes destas adaptações ficam mais evidentes pelo exame de variáveis biomecânicas e eletrofisiológicas como por exemplo o EMG de superfície. A coerência espectral de sinais eletromiográficos dos músculos extensores bilaterais é estatisticamente significativa em duas regiões distintas de frequência $(0-4 \mathrm{~Hz}$ e $8-12 \mathrm{~Hz})$ durante a posição ereta quieta (BOONSTRA et al., 2008). 
Os resultados obtidos por BOONSTRA et al. (2008) para a primeira região de frequência confirmam as assertivas de GIBBS et al. (1995), MOCHIZUKI et al. (2006) e novamente MOCHIZUKI et al. (2007), que sugerem uma ativação muscular mais acentuada em tarefas posturais se comparada com uma tarefa dinâmica.

Os resultados encontrados no presente estudo apontam para uma diminuição significativa na coerência espectral após a intervenção para ambos os grupos, considerando a faixa de $8-12 \mathrm{~Hz}$.

Idosos apresentam aumento significativo na coerência espectral em comparação a adultos jovens saudáveis (OBATTA et al., 2014). Sugere-se que o SNC tende a criar um mecanismo de defesa contra quedas por meio de adaptações no SNC que se refletem em uma estratégia de ativação síncrona de músculos posturais (extensores do tornozelo) em pessoas idosas.

Estes resultados sugerem que o envelhecimento afeta a organização de atividades de músculos posturais bilaterais e unilaterais nos plantares durante a posição ereta (OBATA et al., 2014). Desta forma, os treinos proprioceptivos podem alterar a coerência espectral para freqüências que estão relacionadas com as componentes rápidas do controle motor, no caso freqüências no intervalo de 8 a $12 \mathrm{~Hz}$.

Estudos com idosos como o de BOONSTRA et al. (2008) afirmam que para uma região de freqüência entre $0-4 \mathrm{~Hz}$, a atividade muscular se correlaciona com a oscilação postural. Como neste estudo a amostra não tem problemas no controle postural, pois são escolares adolescentes praticantes de basquetebol sem histórico de lesões nas articulações dos MMII, fica mais difícil de encontrar alguma diferença estatisticamente significativa entre os momentos pré e pós-intervenção para a faixa de frequência entre 0-4 Hz.

MASANI et al. (2007) afirmam que o balanço postural aumenta mais em idosos do que em indivíduos jovens, devido a uma deterioração do controle postural. Este fato acarreta em uma alteração nos comandos descendentes (provenientes de centros supra-segmentares) sobre os motoneurônios medulares. Como a coerência espectral pode estar relacionada com o desempenho na manutenção do equilíbrio corpóreo na postura ereta quieta, sugerimos que a diminuição na coerência espectral na faixa de 8-12 Hz 
observada no presente estudo esteja relacionada com uma melhora de desempenho no controle postural dos sujeitos do GE.

OBATA et al. (2014) sugerem que o envelhecimento afeta a organização das atividades musculares posturais durante a posição tranqüila. Desta forma, idosos tendem a aumentar a coerência espectral devido uma possível deteriorização no sistema de manutenção do controle postural por causa da idade, para adolescentes saudáveis a diminuição da coerência espectral em ambos os grupos indicam uma resposta no SNC para as intervenções aplicadas no GC (treino de basquetebol) e no GE (treino de basquetebol e proprioceptivo), sugerindo assim, uma estratégia do SNC para o controle postural após intervenção com exercícios.

\subsection{Limitações do Estudo}

Uma das limitações do presente estudo foi a falta de controle sobre os treinos de basquetebol realizados pela a amostra durante a intervenção.

Devido aos critérios de inclusão e exclusão, a amostra ficou reduzida a dois grupos de 15 sujeitos no início da pesquisa terminando com um grupo de 15 e outro com 14 sujeitos. Recrutar sujeitos de outras equipes poderia influenciar o método do treino de basquete $e$, consequentemente, os resultados. 


\section{CONCLUSÕES}

Os resultados encontrados no presente estudo mostram que vinte e quatro sessões de treinos proprioceptivos distribuídos em oito semanas em escolares adolescentes praticantes de basquetebol diminuíram significativamente os valores da variável VM na direção ântero-posterior. Este resultado sugere uma melhora no controle postural após o treinamento proprioceptivo..

Houve uma diminuição significativa no valor da coerência espectral na faixa de 8-12 Hz, sugerindo que o controle de oscilações rápidas associadas à atividade bilateral dos músculos posturais foi mais eficiente após a intervenção.

Não foi encontrada nenhuma diferença significativa na variável RMS em nenhuma das direções em nenhum dos grupos demonstrando que o treino tático, técnico e/ou físico do basquetebol ou mesmo a inclusão de treinos proprioceptivos não influenciam de forma significativa o comportamento desta variável.

Com o comportamento do RMS sendo não significativo entre os momentos pré e pós-intervenção nas duas direções (médio-lateral e ântero-posterior), a variável área da elipse se comporta da mesma forma, não demonstrando diferenças significativas em nenhum dos grupos analisados.

Desta maneira é possível entender que vinte e quatro sessões de treinos proprioceptivos em escolares adolescentes praticantes de basquetebol tem resultados estatisticamente significativos na VM somente na direção ântero-posterior e na coerência espectral dos extensores de tornozelos para a faixa de $8-12 \mathrm{~Hz}$.

Os resultados apontam que a utilização de exercícios proprioceptivos somados aos treinos de basquetebol é uma alternativa para a melhora do controle postural para a população com as características deste estudo, e que os treinos de basquetebol conseguem diminuir de forma significativa a coerência espectral dos extensores de tornozelo.

Lembrando da importância de outros estudos com uma amostra de características semelhantes e com mais sessões de treinos, com mais semanas de intervenção, mais sujeitos na amostra e medidas pré-intervenção, coletas intermediárias, pós-intervenção e pelo menos uma medida folow-up para analisar e distinguir o que é efeito agudo do treino e o que é efeito crônico. 


\section{REFERÊNCIAS}

AVELAR, B. P., DE ALMEIDA COSTA, J. N., SAFONS, M. P., DUTRA, M. T., BOTTARO, M., GOBBI, S., GOBBI, S., TIEDEMANN, A., DE DAVID, A. C., \& LIMA, R. M. Balance ExercisesCircuit improves musclestrength, balance, andfunctional performance in olderwomen. $A G E, 38(1), 1-11.2016$.

BARELA, J. A. Estratégias de controle em movimentos complexos: ciclo percepção-ação no controle postural. Revista Paulista de Educação Física. 2000;3:79-88.

BEARD, D. J., KYBERD, P. J., FERGUSSON, C. M., DOOD, C. A. F. Proprioception after rupture of the anterior cruciate ligament. J. Bone Joint Surg, 75:311-315, 1993.

BEYNNON, B. D., HALL, J. S., STURNICK, D. R., DeSARNO, M. J., GARDNER-MORSE, M., TOURVILLE, T. W., VACEK, P. M. IncreasedSlopeofthe Lateral Tibial PlateauSubchondralBonels Associated WithGreaterRiskofNoncontact ACL Injury in FemalesbutNot in Males A ProspectiveCohortStudyWith a Nested, Matched Case-ControlAnalysis. The American journalofsports medicine, 42(5), 1039-1048.(2014).

BOCCOLINI, G.; BRAZZIT, A.; BONFANTI, L.; ALBERTI, G. Using balance training to improve the performance of youth basketball players Sport Sci Health (2013) 9:37-42

BONETTI, L. V.; BRUM, G. R.; MIOTTO, M.; TADIELLO, G. S.; SCHMITT, V. M.; DEMARCHI, T. The use of the taping on ankle stability in basketball athletes. ConScientiaeSaúde, 2012;11(3):491497

BOONSTRA, T. W., DAFFERTSHOFER A, VAN DITSHUIZEN, J. C., VAN DEN HEUVEL, M. R., HOFMAN, C., WILLIGENBURG, N. W., $B E E K, P$. J.Fatigue-related changes in motor-unit synchronization of quadriceps muscles within and across legs. J Electromyogr Kinesiol 18:717-731. 2008

BROGREN, E., HADDERS-ALGRA, M., FORSSBERG, H.. Postural control in sitting children with cerebral palsy. Neuroscience and Biobehavioral Reviews. 1988;22(4):591-6.

CARAFFA, A.; CERULLI, G.; PROJETTI, M.; AISA, G.; RIZZO, A. Prevention of anterior cruciate ligament injuries in soccer. $A$ prospective controlled study of proprioceptive training. Knee Surg, Sports Traumatol, Arthrocopy. 1996 4:19-21.

CLEYS, K., DANKAERTS, W., JANSSENS, L., PIJNENBURG, M., GOOSSENS, N., \& BRUMAGNE, S. Young individuals with a more ankle-steered proprioceptive control strategy may develop mild 
non-specific low back pain. JournalofElectromyographyandKinesiology, 25(2), 329-338. 2015.

COHEN, M., ABDALLA, R. J. Lesões nos Esportes: Diagnóstico, Prevenção e Tratamento. Rio de Janeiro: Revinter; 2005.

COLEMAN, J.; ROKER, D. Puberty. Psychologist, 2013.

COLLET, C. Field dependence-independence in complex motor skills. In Perceptual Motor Skills. 2: 575-583. (2004)

CUMPS, E.; VERHAGEN, E.; MEEUSEN, R. Efficacy of a sports specific balance trainingprogramme on the incidence of ankle sprains in basketball. Journal of Sports Science and Medicine (2007) 6, 212-219.

CUMPS, E.; VERHAGEN, E.; MEEUSEN, R. Prospective epidemiological study of basketball injuries during one competitive season: Ankle sprains and overuse knee injuries Journal of Sports Science and Medicine (2007) 6, 204-211.

DUARTE, M.; FREITAS, S. M . S. F. Revision of posturography based on force plate for balance evaluation. RevBrasFisioter, São Carlos, v. 14, n. 3, p. 183-92, May/June 2010

EILS, E.; ROSENBAUM, D. A multi-station proprioceptive exerciseprogram in patients with ankle instability. MEDICINE \& SCIENCE IN SPORTS \& EXERCISE® copyright (C) 2001 by the American College of Sports Medicine

EMERY, C. A.; MEEUWISSE, W. H. The effectiveness of a neuromuscular prevention strategy to reduce injuries in youth soccer: a cluster-randomised controlled trial. British Journal of Sports Medicine, v. 44, n. 8, p. 555-562, 2010.

ENGEBRETSEN, A. H.; MYKLEBUST, G.; HOLME, I.; ENGEBRETSEN, L.; BAHR, R. Intrinsic risk factors for acute ankle injuries among male soccerplayers: a prospective cohort study. Scand J Med Sci Sports 2009.

FAIZULLIN, I.; FAIZULLINA, E. Effects of balance training on postsprained ankle joint instability. International Journal of Risk \& Safety in Medicine, v. 27, n. s1, p. S99-S101, 2015.

FERDJALLAH M, HARRIS GF, SMITH P, WERTSCH J. Analysis of postural control synergies during quiet standing in healthy children and children with cerebral palsy. Clinical Biomechanics. 2002;17(3):203-10. 
GALLAHUE, D. L., OZMUN, J. C. Compreendendo o Desenvolvimento Motor: bebês, crianças, adolescentes e adultos. São Paulo: Phorte; 2005.

GATEV P, THOMAS S, KEPPLE T, HALLETT M. Feedforward ankle strategy of balance during quiet stance in adults. J Physiol 514(Pt 3):915-928. 1999.

GIBBS, J., HARRISON, L. M., STEPHENS, J. A. Organizationof inputs tomotoneurone pools in man. J Physiol 485(Pt 1):245-256. (1995)

GRATHWOHL, S., MONVERT, A., \& PICHONNAZ, C.. Evaluationdutraitementpréventif de l'entorse de chevilleavecledispositif de proprioceptionMyolux ${ }^{\circledR}$ chez lehandballeuramateur. Haute écolecantonalevaudoise de lasanté. (2006)

HADDERS-ALGRA, M. Development of postural control during the first 18 months of life. Neural Plasticity. 2005;12(2-3):99-108.

HERMAN, K.; BARTON, C.; MALLIARAS, P.; MORRISSEY, D. The effectiveness of neuromuscular warm-up strategies, that require no additional equipment, for preventing lower limb injuries during sports participation: a systematic review. BMC Medicine 2012, 10:75 http://www.biomedcentral.com/1741-7015/10/75

HOLM, I., FOSDAHL, M. A., FRIIS, A., RISBERG, M. A., MYKLEBUST, G., Harald STEEN, H. Effect of Neuromuscular Training on Proprioception, Balance, Muscle Strength, and Lower Limb Function in Female TeamHandball Players. Clin J Sport Med • Volume 14, Number 2, March 2004

HORAK, F. B., \& NASHNER, L. M. Central programming of postural movements: adaptation to altered support-surface configurations. Journal of neurophysiology, 55(6), 1369-1381. (1986).

HORAK, F. B. Postural orientation and equilibrium: what do we need to know about neural control of balance to prevent falls? Age and Ageing 2006;35:117-21.

HSU, Y. S., KUAN, C. C., YOUNG, Y. H. Assessing the development of balance function in children using stabilometry. International Journal of Pediatric Otorhinolaryngology. 2009;73:737-40.

HÜBSCHER, M, ZECH, A, PFEIFER, K, HÄNSEL, F, VOGT, L, and BANZER, W. Neuromuscular training for sports injury prevention: a systematic rewiew. Med Sci Sports Exerc. 42(3): 413:21, 2010. 
KOUZAKI M, MASANI K. Postural sway during quiet standing is related to physiological tremor and muscle volume in young and elderly adults. Gait Posture 35:11-17. 2012

LATASH, M. L.; SCHOLZ, J. P.; SCHÖNER, G.. Toward a new theory of motor synergies. Permagon Press, 2012.

LEE, J. C., KIM, J. Y., \& PARK, G. D. Effect of 12 weeks of accelerated rehabilitation exercise on muscle function of patients with ACL reconstruction of the knee joint. Journal of physical therapy science, 25(12), 1595. 2013.

LEE, C. W., HWANGBO, K. The Effects of Combination Patterns of Proprioceptive Neuromuscular Facilitation and Ball Exercise on Pain and Muscle Activity of Chronic Low Back Pain Patients. J. Phys. Ther. Sci. Vol. 26, No. 1, 2014

LIAO, H. F., HWANG, A. W. Relations of balance function and gross motor ability for children with cerebral palsy. Perceptual and Motor Skills. 2003;96(3 Pt 2):1173-84.

MAJLESI, M., FARAHPOUR, N., AZADIAN, E., \& AMINI, M..The effectofinterventionalproprioceptive training onstatic balance andgait in deafchildren. Research in developmentaldisabilities, 35(12), 3562-3567. (2014)

MANDELBAUM, B. R.; SILVERS, H. J.; WATANABE, D. S., KNARR, J. F.; THOMAS, S. D.; GRIFFIN, L. Y.; KIRKENDALL, D. T.; GARRET, W. Effectiveness of a Neuromuscular and Proprioceptive Training Program inPreventing the Incidence of Anterior Cruciate Ligament Injuries in Female Athletes 2-Year Follow-up. The American Journal of Sports Medicine. Vol. 33, No. 7, 2005.

MARTINEZ-AMAT, A., HITA-CONTRERAS, F., LOMAS-VEGA, R., CABALLERO-MARTINEZ, I., ALVAREZ, P. J., MARTINEZ-LOPEZ, E. (2012). Effects of 12-week proprioception training program on postural stability, gait and balance in older adults: A controlled clinical trial.J Strength Cond Res. doi: 10.1519/JSC.0b013e31827da35f. 2013.

MASANI, K., VETTE, A. H., KOUZAKI, M., KANEHISA, H., FUKUNAGA, T., \& POPOVIC, M. R. Larger center of pressure minus center of gravity in the elderly induces larger body acceleration during quiet standing.Neuroscience letters, 422(3), 202-206. (2007).

McCRISKIN, B. J., CAMERON, K. L., ORR, J. D. 7 WATERMAN, B. $R$..Management and prevention of acute and chronic lateral ankle instability in athletic patient populations. World journal of orthopedics, v. 6, n. 2, p. 161, 2015. 
McLEOD, T. C. V. The Effectiveness of Balance Training Programs on Reducing the Incidence of Ankle Sprains in Adolescent Athletes. Journalof Sport Rehabilitation, 2008, 17, 1-8 (c) 2008 HumanKinetics, Inc.

MEZZARANE, R. A., KOHN, A.F. Control of upright stance over inclined surfaces. Experimental Brain Research, 180: 377-388. 2007.

MEZZARANE, R. A., \& KOHN, A. F. Postural controlduringkneeling. Experimentalbrainresearch, 187(3), 395-405. (2008).

MEZZARANE, R.A.; KOHN, A.F. A method to estimate EMG crosstalk between two muscles based on the silent period following an H-reflex. Medical Engineering \& Physics, 31(10):1331-6. 2009.

MOCHIZUKI, G., SEMMLER, J. G., IVANOVA, T. D., GARLAND, S. J. Low-frequency common modulationofsoleus motor unitdischargeisenhancedduring postural control in humans. ExpBrain Res 175:584-595. (2006)

MOCHIZUKI, G., IVANOVA, T. D., GARLAND, S. J. Factorsaffectingthe common modulationof bilateral motor unitdischarge in humansoleusmuscles. J Neurophysiol 97:39173925. (2007)

NATINONAL FEDERATION OF STATE HIGH SCHOOL ASSOCIATIONS HANDBOOK: 2004-2005 High School Athletics Participation Survey. Indianapolis, IN: National Federation of State High School Associations; 2005.

OBATA, H., ABE, M. O., MASANI, K., \& NAKAZAWA, K. Modulation between bilateral legs and within unilateral muscle synergists of postural muscle activity changes with development and aging. Experimental brain research, 232(1), 1-11. 2014.

OLIVEIRA, D. C. S. D., REZENDE, P. A. M. D. S., SILVA, M. R. D., LIZARDO, F. B., SOUSA, G. D. C., SANTOS, L. A. D., CHACUR, E. P. Electromyographic analysis of lower limb Muscles in proprioceptive exercises performed With eyes open and closed. Revista Brasileira de Medicina do Esporte, 18(4), 261-266. 1986.

OLIVEIRA, L. F., IMBIRIBA, L. A., GARCIA, M. A. C. Índice de estabilidade para avaliação do equilíbrio postural. Revista Brasileira de Biomecânica. 2000;1(1):33-8.

OLIVEIRA, T. P., SANTOS, A. M. C., ANDRADE, M. C., ÁVILA, A. O. V. Avaliação do controle postural de crianças praticantes e não 
praticantes de atividade física regular. Revista Brasileira de Biomecânica. 2008;9(16):41-6.

ORLIN, M. N., McPOIL, T. G. Plantar pressure assessment Physical Therapy. 2000;80(4):399-409.

OSBOURNE, M. D., CHOU, L. S., LASKOWSKI, E. R., SMITH, J., KAUFMAN, K. R..The effectofankle disk training onmusclereaction time in subjectswith a historyofanklesprain. Am J Sports Med2001;29:627-32. 2008

PALMIERI, R. M., INGERSOLL, C. D., STONE, M. B., KRAUSE, B. A. Center-of-pressure parameters used in the assessment of postural control. Journal of Sport Rehabilitation. 2002(11):51-66.

PARKKARI, J.; TAANILA, H.; SUNI J.; MATTILA, V. M.; VUORINEN, P.; KANNUA, P. Neuromuscular training with injury prevention counselling to decrease the risk of acute musculoskeletal injury in young men during military service: a population-based, randomised study. BMC Med 2011, 9:35.

PASANEN, K.; PARKKARI, J.; PASANEN, M.; HIILLOSKORPI, H.; KANNUS, P. Neuromuscular training and the risk of leg injuries in female floorball players: cluster randomised controlled study. BMJ 2008;337:a295 doi:10.1136/bmj.a295

PLISKY, P. J.; RAUH, M. J.; KAMINSKI, T. W.; UNDERWOOD, F. B. Star Excursion Balance Test as a Predictor of Lower Extremity Injury in High School Basketball Players. Orthop Sports PhysTher 2006;36(12):911-919. doi:10.2519/jospt.2006.2244

POLLOCK, A. S., DURWARD, B. R., ROWE, P. J., PAUL, J. P. C. R. What is balance? Clinical Rehabilitation. 2000;14(4):402-6.

POWELL, J. W., BARBER-FOSS, K. D. Injury Patterns in Selected High School Sports: A Review of the 1995-1997 Seasons. J AthITrain. 1999;34:277-284.

PURVES, D., AUGUSTINE G. J., FITZPATRICK, D., HALL, W. C., LAMANTIA, A. S., MACNAMARA, J. O., WILLIAMS, S. M., Neuroscience. Sinauer Associates. 3rd Ed. Sunderland, 2004.

RÉ, A. H. N. Crescimento, maturação e desenvolvimento na infância e adolescência: Implicações para o esporte. Motricidade, v. 7, n. 3, p. 55-67, 2011.

RIEMANN, B. L., LEPHART, S. M. The Sensorimotor System, Part II: The Role of Proprioception in Motor Control and Functional Joint Stability. Journal of Athletic Training. 2002; 37(1):80-84 
ROSENBAUM, D. A. Human motor control . San Diego, CA: Academic Press, 2011.

ROSENBERG, J. R., HALLIDAY, D. M., BREEZE, P., CONWAY, B. A.Identification of patterns of neuronal connectivity-partial spectra, partial coherence, and neuronal interactions. J Neurosci Methods 83:57-72. 1998.

ROSS, B. L., Proprioceptive exercises balance ankle stability and activity.The combination of exercises may reduce the chance of recurrent ankle sprains andreinjury. The Magazine of Body Movement and Medicine. 2006.

ROSS, S. E.,GUSKIEWICZ, K. M., GROSS, M. T., YU, I. Balance Measures for Discriminating between Functionally Unstable and Stable Ankles. MEDICINE \& SCIENCE IN SPORTS \& EXERCISE8 COPyright (C) 2009 by the American College of Sports Medicine.

ROZZI, S. L., LEPHART, S. M., STERNER, R., KULIGOWSKI, L. Balance training for personswithfunctionallyunstableankles. J Orthop Sports Phys Ther 1999; 29: 478-86.

RUGELJ, D., SEVSEK, F. Analysis of Postural Sway Data of Elderly Subjects. International Conference on Signal Processing, Robotics and Automation; 2007 February 16-19, 2007; Corfu Island, Greece.

SAITO, M. I., SILVA, L. E., LEAL, M. M. Adolescência: prevenção e risco. São Paulo: Atheneu; 2011.

SHETH, P., YU, B., LASKOWSKI, R. E., AN, K. Ankle Disk Training Influences Reaction Times of Selected Muscles in a Simulated Ankle Sprain. Journal of Sports Medicine, Vol. 25, No 4, 1997.

SHIM, A. L., STEFFEN, K., HAUER, P., CROSS, P., VAN RYSSEGEM, G. The Effects of Balance Training on Stability and Proprioception Scores of the Ankle in College Students. International Journal of Kinesiology and Sports Science, 3(4), 16-21. 2015.

SHUMWAY-COOK, A., HUTCHINSON, S., KARTIN, D., PRICE, R., WOLLACOTT, M. Effect of balance training on recovery of stability in children with cerebral palsy. Developmental Medicine \& Child Neurology. 2003;45:591-602.

SMETANA, J. G. Adolescents' and parents' conceptions of parental authority. CanadianEdition, 2013.

STEEN, H., HOLM, P. T.; RISBERG, M. A. Effect of neuromuscular training on proprioception, balance, muscle strength, and lower 
limb function in female team handball players. ClinicalJournal Sport Medice. 2004;14:88-94.

SUDA, E. Y., COELHO, A. T. Instrumentos de avaliação para limitações funcionais associadas à instabilidade crônica de tornozelo: uma revisão sistemática da literatura. Fisioter. Pesqui.,v.19,n.1,p.79-85,2012

SHUMWAY-COOK, A., HUTCHINSON, S., KARTIN, D., PRICE, R., WOLLACOTT, M. Effect of balance training on recovery of stability in children with cerebral palsy. Developmental Medicine \& Child Neurology. 2003;45:591-602.

TAUBE, W.; KULLMANN, N.; LEUKEL, C.; KURZ, O.; AMTAGE, F.; GOLLHOFER, A. Differential reflex adaptations following sensorimotor and strength training in young elite athletes. International journal of sports medicine, 28(12), 999-1005. 2007.

TEREKHOV, Y. Stabilometry as diagnostic tool in clinical medicine. Canadian Medical Association Journal. 1976;115(7):631-3.

VERHAGEN, E.; BEEK, A., TWISK, J.; BOUTER, L., BAHR, R.; MECHELEN, W. The effect of a proprioceptive balance board training program for the prevention of ankle sprains. The American Journal of Sports Medicine. Vol. 32, n. 6, 2004.

VUILLERME, N., NOUGIER, V., PRIEUR, J. Canvisioncompensate for a lowerlimbs muscular fatigue for controllingposture in humans? NeuroscienceLetters, 308, 103-106. 2001

WAJDA, D. A., MOTL, R. W., \& SOSNOFF, J. J..Three-Month TestRetestReliabilityof Center ofPressure Motion DuringStanding Balance in IndividualswithMultipleSclerosis. InternationalJournalof MS Care. 2015

WINTER, D. A. A.B.C. (Anatomy, Biomechanics, and Control) of Balance during Standing and Walking. Waterloo, Ontario, Waterloo Biomechanics, 1995.

WINTER, D. A. Human balance and posture control during standing and walking. Gait Posture. 1995;3:193-214.

ZOUITA, A. B. M., MAJDOUB, O., FERCHICHI, H., GRANDY, K., DZIRI, C., \& SALAH, F. B. The effect of 8-weeks proprioceptive exercise program in postural sway and isokinetic strength of ankle sprains of Tunisian athletes. Annalsofphysicalandrehabilitation medicine, 56(9), 634-643, 2013. 


\section{ANEXOS}




\section{FACULDADE DE EDUCAÇÃo FísICA CAMPUS UNIVERSITÁRIO DARCY RIBEIRO UnB BRASILIA-DF}

\section{ANEXO A -Termo de Consentimento Livre e Esclarecido}

$O$ (a) seu(sua) filho(a) está sendo convidado(a) a participar do projeto "Análise dos efeitos de um programa de treinamento proprioceptivo sobre 0 equilíbrio postural e sobre a excitabilidade de reflexos de escolares praticantes e não praticantes de basquetebol" sob a responsabilidade do pesquisador Prof. Dr. Rinaldo André Mezzarane. O projeto consiste em realizar medidas reflexas e de oscilação postural antes e após um treinamento de equilíbrio (ou treinamento proprioceptivo).

O objetivo da pesquisa é aprofundar o conhecimento do controle dos movimentos relacionados ao esporte e ajudar a evitar lesões decorrentes da prática esportiva. O treinamento de equilíbrio poderá resultar em uma melhora no controle dos movimentos com vistas à prevenção de lesões.

Todos os esclarecimentos necessários serão prestados antes e no decorrer da pesquisa e lhes asseguramos que a identidade de seu(sua) filho(a) será mantida no mais rigoroso sigilo.

A participação se dará por meio do preenchimento de um questionário, análise do equilíbrio postural em pé sobre uma plataforma de força, e realização de testes de salto e aterrissagem simulando bandeja e rebote do basquete. Serão aplicados estímulos elétricos de baixa intensidade próximos ao joelho por meio de eletrodos. Estes eletrodos serão fixados na perna por meio de uma fita antialérgica. Um estímulo mecânico de baixa intensidade será aplicado no tendão de Aquiles por meio de um aparelho. Nenhum dos testes provoca desconforto ou dor e seu(sua) filho(a), que estará sendo monitorado(a) pelo pesquisador, deverá relatar em qualquer momento eventuais dores ou qualquer tipo de desconforto, podendo desistir do experimento se assim o desejar. As medidas e as intervenções são extremamente seguras. Existe risco mínimo associado a possíveis quedas durante o treinamento, contudo os participantes estarão realizando atividades supervisionadas por um professor de Educação Física que aplicará atividades orientadas, minimizando os riscos. Os experimentos serão realizados no Laboratório de Processamento de Sinais Biológicos e Controle Motor da Faculdade de Educação Física da UnB. O tempo estimado para a realização de todas as etapas do experimento será de aproximadamente três horas. Após os testes inicias o(a) seu(sua) filho(a) participará de um regime de treinamento de equilíbrio por oito semanas. Esses treinos serão realizados na escola de seu(sua) filho(a). Após as oito semanas o mesmo procedimento da primeira visita será repetido. As visitas serão agendadas de acordo com a disponibilidade.

$O$ (A) Senhor(a), ou o(a) seu(sua) filho(a), podem se recusar a participar de qualquer procedimento ou responder qualquer questão que Ihes tragam constrangimento, podendo desistir de participar da pesquisa em qualquer 
momento sem nenhum prejuízo para o(a) Senhor(a) ou para o(a) seu(sua) filho(a) e sem a necessidade de prover explicações adicionais. A participação de seu(sua) filho(a) é voluntária, isto é, não há pagamento por sua colaboração. Despesas relacionadas diretamente ao transporte para o laboratório serão cobertas pelo pesquisador responsável. Caso haja algum dano direto resultante dos procedimentos de pesquisa, o(a) Senhor(a) poderá ser indenizado(a), obedecendo-se as disposições legais vigentes no Brasil.

Os resultados da pesquisa serão divulgados na Faculdade de Educação Física da Universidade de Brasília podendo ser publicados posteriormente. Os dados e materiais utilizados na pesquisa ficarão sob a guarda do pesquisador por um período de no mínimo cinco anos, após isso serão destruídos ou mantidos na instituição.

Se o(a) Senhor(a) tiver qualquer dúvida adicional em relação à pesquisa, por favor telefone para: Prof. Dr. Rinaldo André Mezzarane ou Prof. Dr. Tiago Guedes Russomanno no telefone (61) 3107-2526, da Faculdade de Educação Física da Universidade de Brasília, no horário comercial. Este projeto foi aprovado pelo Comitê de Ética em Pesquisa da Faculdade de Ciências da Saúde da Universidade de Brasília. As dúvidas com relação à assinatura do TCLE ou os direitos do sujeito da pesquisa podem ser esclarecidas pelo telefone: (61) 3107-1947 ou do e-mail cepfs@unb.br, horário de atendimento de $10 \mathrm{hs}$ às $12 \mathrm{hs}$ e de $14 \mathrm{hs}$ às $17 \mathrm{hs}$, de segunda a sexta-feira. Este documento foi elaborado em duas vias, uma ficará com o pesquisador responsável e a outra com o sujeito da pesquisa.

Nome do Responsável:

Pesquisador: Rinaldo André Mezzarane

Brasília, de de 


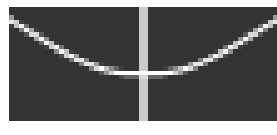

UnB BRASILIA-DF
FACULDADE DE EDUCAÇÃO FÍSICA

CAMPUS UNIVERSITÁRIO DARCY RIBEIRO

\section{ANEXO B -Termo de Assentimento Livre e Esclarecido}

Você está sendo convidado(a) a participar de uma pesquisa com o título "Análise dos efeitos de um programa de treinamento proprioceptivo sobre o equilíbrio postural e sobre a excitabilidade de reflexos de escolares praticantes e não praticantes de basquetebol" para estudar o controle dos movimentos. $O$ responsável pela pesquisa é o Professor Rinaldo André Mezzarane. Esta pesquisa é importante, pois irá ajudar a evitar lesões durante o jogo de basquete.

Pesquisa é um conjunto de testes que serão feitos em você, se você concordar em participar. Assentimento significa que você concorda em fazer parte de um grupo de estudantes, da sua faixa de idade, para participar da pesquisa.

Por favor, peça a algum membro da equipe para explicar qualquer palavra ou informação que você não entenda. Você poderá fazer qualquer pergunta antes do início e durante os testes.

Se você concordar em participar, o pesquisador pedirá para você preencher um questionário e ficar em pé sobre um quadrado de metal localizado no chão. Você também fará movimentos de bandeja e rebote do basquete, mas sem bola. Depois você irá sentar em uma cadeira e um estímulo elétrico bem fraco será aplicado na parte de trás ou do lado do joelho com um disco de metal. O estímulo não dói, apenas dá uma sensação de coceira ou beliscão fraco. Em seguida, um estímulo mecânico fraco (leve batida) será aplicado logo acima do calcanhar com um aparelho. O estímulo mecânico também não dói. Se você se sentir incomodado ou com dor, avise o pesquisador ou qualquer pessoa da equipe. Os testes em que você vai participar têm três horas de duração no total, e serão realizados na Faculdade de Educação Física da UnB. 
Quando terminar os testes, você irá participar de um treinamento de equilíbrio em sua escola durante oito semanas, junto com o treino de basquete. Existe risco de queda durante os treinos, mas o professor de Educação Física sempre estará por perto orientando os exercícios para que não ocorram quedas. Após os treinos, você irá voltar para a Faculdade e vai repetir os testes. Você poderá desistir de participar dos testes quando quiser, sem precisar explicar a razão.

Você não vai receber dinheiro para participar nos testes.

Os resultados obtidos dos testes serão publicados em revistas científicas, mas o seu nome não será divulgado.

Nome do Responsável:

Nome do Participante:

Pesquisador: Rinaldo André Mezzarane

Brasília, de de 


\section{ANEXO C -AJFAT}

Nome:

1. Como você descreveria o nível de dor que você sente em seu tornozelo?

(0) muito maior em um do que no outro tornozelo

(1) um pouco maior em um do que no outro tornozelo

(2) não sinto dor nos tornozelos

(3) ligeiramente menor em um do que no outro tornozelo

(4) muito menor em um do que no outro tornozelo

2. Como você descreveria qualquer inchaço do tornozelo?

(0) muito maior em um do que no outro tornozelo

(1) um pouco maior em um do que no outro tornozelo

(2) não possuo inchaço nos tornozelos

(3) ligeiramente menor em um do que no outro tornozelo

(4) muito menor em um do que no outro tornozelo

3. Como você descreveria a capacidade de seu tornozelo ao andar em superfícies irregulares?

(0) muito maior em um do que no outro tornozelo

(1) um pouco maior em um do que no outro tornozelo

(2) igual nos dois tornozelos

(3) ligeiramente menor em um do que no outro tornozelo

(4) muito menor em um do que no outro tornozelo

4. Como você descreveria a sensação geral de estabilidade de seu tornozelo?

(0) muito menos estável em um do que no outro tornozelo

(1) um pouco menos estável em um do que no outro tornozelo

(2) estabilidade igual nos dois tornozelos

(3) um pouco mais estável em um do que no outro tornozelo

(4) muito mais estável em um do que no outro tornozelo 
5. Como você descreveria a sensação geral de força de seu tornozelo?

(0) muito menos forte em um do que no outro tornozelo

(1) um pouco menos forte em um do que no outro tornozelo

(2) igual em força entre os tornozelos

(3) ligeiramente mais forte em um do que no outro tornozelo

(4) muito mais forte em um do que no outro tornozelo

6. Como você descreveria sua capacidade nos tornozelos quando você desce escadas?

(0) muito menor em um do que no outro tornozelo

(1) ligeiramente menor em um do que no outro tornozelo

(2) igual entre os tornozelos

(3) um pouco maior em um do que no outro tornozelo

(4) muito maior em um do que no outro tornozelo

7. Como você descreveria sua capacidade nos tornozelos quando você corre?

(0) muito menor em um do que no outro tornozelo

(1) ligeiramente menor em um do que no outro tornozelo

(2) igual entre os tornozelo

(3) um pouco maior em um do que no outro tornozelo

(4) muito maior em um do que no outro tornozelo

8. Como você descreve a capacidade dos seus tornozelos para "cortar", ou mudar de direção quando você está correndo?

(0) muito menor em um do que no outro tornozelo

(1) ligeiramente menor em um do que no outro tornozelo

(2) igual entre os tornozelo

(3) um pouco maior em um do que no outro tornozelo

(4) muito maior em um do que no outro tornozelo 
9. Como você descreveria o nível global de atividade de seu tornozelo?

(0) muito menor em um do que no outro tornozelo

(1) ligeiramente menor em um do que no outro tornozelo

(2) igual entre os tornozelo

(3) um pouco maior em um do que no outro tornozelo

(4) muito maior em um do que no outro tornozelo

10. Qual situação melhor descreve sua capacidade de sentir o tornozelo começando a "pisar em falso"?

(0) muito mais tarde do que o outro tornozelo

(1) um pouco mais tarde do que o outro tornozelo

(2) ao mesmo tempo como no outro tornozelo

(3) um pouco mais cedo do que o outro tornozelo

(4) muito mais cedo do que o outro tornozelo

11. Comparando os tornozelos, qual situação melhor descreve a sua capacidade de respota do seu tornozelo quando "pisa em falso"?

(0) muito mais tarde do que o outro tornozelo

(1) um pouco mais tarde do que o outro tornozelo

(2) ao mesmo tempo nos dois tornozelos

(3) um pouco mais cedo do que o outro tornozelo

(4) muito mais cedo do que o outro tornozelo

12. Na sequência de um incidente (torcer, "pisar em falso", cair, tropeçar), qual situação melhor descreve o tempo necessário para voltar à atividade?

(0) mais de 2 dias

(1) 1 a 2 dias

(2) mais de 1 hora e menos de 1 dia

(3) 15 minutos a 1 hora

(4) quase imediatamente 


\section{ANEXO D - IPAQ (Versão Curta)}

Nome:

Você trabalha de forma remunerada: ( ) Sim ( ) Não

Quantas horas você trabalha por dia:

Quantos anos completos você estudou:

De forma geral sua saúde está:

( ) Excelente ( ) Muito boa ( ) Boa

Para responder as questões lembre que:

- atividades físicas VIGOROSAS são aquelas que precisam de um grande esforço físico e que fazem respirar MUITO mais forte que o normal;

- atividades físicas MODERADAS são aquelas que precisam de algum esforço físico e que fazem respirar UM POUCO mais forte que o normal;

Para responder as perguntas pense somente nas atividades que você realiza por pelo menos 10 minutos contínuos de cada vez:

1a. Em quantos dias de uma semana normal, você realiza atividades VIGOROSAS por pelo menos 10 minutos contínuos, como por exemplo correr, fazer ginastica aeróbica, jogar futebol, pedalar rápido na bicicleta, jogar basquete, fazer serviços domésticos pesados em casa, no quintal ou no jardim, carregar pesos elevados ou qualquer atividade que faça você suar BASTANTE ou aumentem MUITO sua respiração ou batimentos do coração?

dias: por SEMANA $\quad(\quad)$ Nenhum 
1b. Nos dias em que você faz essas atividades vigorosas por pelo menos 10 minutos contínuos, quanta tempo no total você gasta fazendo essas atividades por dia?

horas: Minutos:

2a. Em quantos dias de uma semana normal, você realiza atividades MODERADAS por pelo menos 10 minutos contínuos, como por exemplo, pedalar leve na bicicleta, nadar, dançar, fazer ginástica aeróbica leve, jogar vôlei recreativo, carregar pesos leves, fazer serviços domésticos na casa, no quintal ou no jardim como varrer, aspirar, cuidar do jardim, ou qualquer atividade que faça você suar leve ou aumentem moderadamente sua respiração ou batimentos do coração (POR FAVOR NAO INCLUA CAMINHADA)

horas: Minutos:

2b. Nos dias em que você faz essas atividades moderadas por pelo menos 10 minutos contínuos quanta tempo no total você gasta fazendo essas atividades por dia?

horas: Minutos:

3a. Em quantos dias de uma semana normal você caminha por pelo menos 10 minutos contínuos em casa ou no trabalho, como forma de transporte para ir de um lugar para outro, por lazer, por prazer ou como forma de exercício?

dias: por SEMANA $\quad(\quad)$ Nenhum 
3b. Nos dias em que você caminha por pelo menos 10 minutos contínuos quanta tempo no total você gasta caminhando por dia?

horas: Minutos:

4a. Estas ultimas perguntas são em relação ao tempo que você gasta sentado ao todo no trabalho, em casa, na escola ou faculdade e durante o tempo livre. Isto inclui o tempo que você gasta sentado no escritório ou estudando, fazendo lição de casa, visitando amigos, lendo e sentado ou deitado assistindo televisão.

Quanto tempo por dia você fica sentado em um dia da semana? Horas: Minutos:

4b. Quanto tempo por dia você fica sentado no final de semana? Horas: Minutos: 


\section{ANEXO E - QUESTIONÁRIO DE CARACTERIZAÇÃO}

\section{ANAMNESE}

Nome:

Idade: Data de Nascimento:

Endereço:

CEP:

Telefones:

Escolaridade:

Nome dos responsáveis:

\section{CARACTERÍSTICAS FÍSICAS}

Massa Corporal: Kg Estatura: m

Membro Dominante:

Posição em Quadra: (1) Armador (2) Ala Armador (3) Ala (4) Ala Pivô (5) Pivô Realiza alguma outra atividade física orientada ou não além do basquetebol?

$$
\text { ( ) Sim ( ) Não }
$$

Qual?:

Frequência semanal (horas):

\section{HISTÓRICO DO ATLETA}

Tempo de treinamento (em meses):

Frequência semanal atual (horas):

Tem algum conhecimento sobre Treinos Proprioceptivos?

$$
\text { ( ) Sim ( ) Não }
$$




\section{HISTÓRICO DE LESÕES:}

Já realizou alguma cirurgia em membros inferiores. ( ) SIM ( ) NÃO

Qual?:

Nos últimos 6 meses sofreu alguma lesão de membros inferiores?

$$
\text { ( ) SIM ( ) NÃO }
$$

Qual?:

Essa lesão ocorreu: Em treino ( ) Em jogo ( ) Fora de Quadra ( )

Foi necessário afastamento das atividades relacionadas ao basquete por conta da lesão?

$$
\text { ( ) SIM ( ) NÃO. }
$$

Por quanto tempo?:

Realizou tratamento fisioterapêutico para essa lesão?

$$
\text { ( ) } \operatorname{SIM}(\text { ) NÃO }
$$

Usa órtese em treino?

$$
\text { ( ) SIM ( ) NÃO }
$$

Quais?:

Por qual motivo usa?

Uso de órtese em jogo? ( ) SIM ( ) NÃO

Quais?:

Por qual motivo usa? 
ANEXO F -PARECERCEP/UnB

FACULDADE DE CIÊNCIAS DA
SAÚDE DA UNIVERSIDADE DE Plotoforma
BnB
BRASÍLIA - CEP/FS-UNB

PARECER CONSUBSTANCIADO DO CEP

DADOS DO PROJETO DE PESQUISA

Título da Pesquisa: Análise dos efeitos de um programa de treinamento proprioceptivo sobre o equilibrio postural e sobre a excitabilidade de reflexos de escolares praticantes e não praticantes de basquetebol

Pesquisador: Rinaldo André Mezzarane

Área Temática:

Versão: 2

CAAE: 33939514.9 .0000 .0030

Instituição Proponente: Faculdade de Educação Física - UnB

Patrocinador Principal: MINISTERIO DA CIENCIA, TECNOLOGIA E INOVACAO

DADOS DO PARECER

Número do Parecer: 788.170

Data da Relatoria: 10/09/2014 